\title{
Geologia e geocronologia do Charnockito São Francisco Xavier e do Gabronorito Ribeirão do Paiol (MG/SP) e suas possíveis relações com processos crustais extensionais nos orógenos Brasília Meridional e Ribeira Central
}

Geology and geochronology of São Francisco Xavier Charnockite (MG, Brazil) and Ribeirão do Paiol Gabbronorite (SP, Brazil) and its possible relations with extensional crustal processes in the Southern Brasilia and Central Ribeira orogens

\author{
Rodrigo Vinagre da Costa ${ }^{1}$, Rudolph Allard Johannes Trouw ${ }^{1}$, Julio Cezar Mendes ${ }^{1}$ \\ 'Departamento de Geologia, Instituto de Geociências, Universidade Federal do Rio de Janeiro - UFRJ, Avenida Athos \\ da Silveira Ramos, 274, bloco J, Campus Ilha do Fundão, Cidade Universitária, CEP 21949-900, Rio de Janeiro, RJ, BR \\ (rodrigogeologo@yahoo.com.br; rajtrouw@hotmail.com; julio@geologia.ufrj.br)
}

Recebido em 29 de março de 2016; aceito em 01 de fevereiro de 2018

\begin{abstract}
Resumo
Na região entre as cidades de São Francisco Xavier, Monteiro Lobato, Campos do Jordão e São Bento do Sapucaí, estão expostas rochas metamórficas de fácies granulito de média pressão a anfibolito, associadas a Nappe Socorro e ao Terreno Embu. O Gabronorito Ribeirão do Paiol e o Charnockito São Francisco Xavier constituem corpos magmáticos encaixados em metagranitoides do Batólito Serra da Água Limpa. O Gabronorito Ribeirão do Paiol é isotrópico, tem textura inequigranular seriada hipidiomórfica a xenomórfica e idade de cristalização U-Pb LA-ICPMS de $534 \pm 6$ Ma. O Charnockito São Francisco Xavier possui textura isotrópica, equigranular a inequigranular seriada hipidiomórfica a xenomórfica e idade de cristalização entre $579 \pm 5$ Ma (núcleo dos grãos) e $562 \pm 8$ Ma (borda dos grãos), compatível com a evolução da Faixa Ribeira Central. O geotermômetro baseado em saturação de zircônio em rocha total aponta temperatura de cristalização de aproximadamente $880^{\circ} \mathrm{C}$ para o charnockito. Os dois corpos exibem valores de $\varepsilon_{\mathrm{Nd}}(\mathrm{t})$ negativos $(-7,32$ para o gabronorito e -12,41 para o charnockito), indicando contaminação e /ou origem crustal do magma gerador de ambos.
\end{abstract}

Palavras-chave: Faixa Brasília Meridional; Faixa Ribeira Central; Geocronologia; Rochas magmáticas.

\begin{abstract}
Metamorphic rocks of medium pressure granulite to amphibolites facies of Socorro Nappe and Embu Terrane crop out extensively in the border region between the states of São Paulo and Minas Gerais, close to the towns of São Francisco Xavier, Monteiro Lobato, Campos do Jordão e São Bento do Sapucaí. Ribeirão do Paiol Gabbronorite and São Francisco Xavier Charnockite are igneous bodies hosted by metagranitoids belonging to the Serra da Água Limpa batholith. Ribeirão do Paiol Gabbronorite is isotropic and shows a hypidiomorphic to xenomorphic inequigranular seriate texture. U-Pb in zircon LA-ICPMS analyses yield a crystallization age of $534 \pm 6$ Ma for this unit. São Francisco Xavier Charnockite exhibits an igneous, isotropic equigranular to hypidiomorphic inequigranular texture. $\mathrm{U}-\mathrm{Pb}$ in zircon crystallization ages ranging from $579 \pm 5 \mathrm{Ma}$ in the cores to $562 \pm 8 \mathrm{Ma}$ in the rims were obtained for this body, indicating its generation occurred during the evolution of the Central Ribeira Belt. The whole rock zirconium saturation geothermometer indicates temperature around $880^{\circ} \mathrm{C}$ for the crystallization of the charnockitic magma. Negative $\varepsilon_{\mathrm{Nd}}(\mathrm{t})$ values were obtained for both bodies $(-7.32$ for the gabbronorite, and -12.41 for the charnockite), revealing significant crustal contribution in the respective magmas.
\end{abstract}

Keywords: Southern Brasília Belt; Central Ribeira Belt; Geochronology; Magmatic rocks. 


\section{INTRODUÇÃO}

O estudo e a compreensão das rochas ígneas geradas durante um ciclo orogenético são fundamentais para a determinação da participação de fontes mantélicas e/ou crustais na geração de magmas que se diversificam cristalizando rochas com variadas composições, estruturas e texturas (Wilson, 1989; Best, 1982; Condie, 1989; Winter, 2010).

As rochas ígneas básicas correspondem a uma pequena parcela da crosta continental terrestre e constituem uma importante fonte de informação relativa ao manto. Por outro lado, granitoides predominam nos continentes e, normalmente, são produtos de fusão crustal de vários tipos de fonte. Porém, granitoides também podem derivar diretamente do manto por meio de fracionamento magmático, maneira pela qual foram gerados os primeiros continentes da Terra.

Considerando tais premissas, este trabalho focaliza aspectos petrográficos, isotópicos e geocronológicos (U-Pb em zircão) de duas ocorrências de rochas ígneas que afloram no leste do estado de São Paulo: o Gabronorito Ribeirão do Paiol e o Charnockito São Francisco Xavier. Esses plutons estão alojados em rochas consideradas como pertencentes à Faixa Brasília Meridional (Trouw et al., 2000; Campos Neto et al., 2004), e este trabalho teve o intuito de investigar se a época de formação desses corpos está relacionada à evolução da Faixa Brasília ou da Faixa Ribeira Central.

\section{MÉTODOS ANALÍTICOS}

A petrografia foi realizada a partir do estudo de nove lâminas, sendo quatro do gabronorito e cinco do charnockito. A composição modal foi baseada em contagem de 800 pontos por lâmina.

Os elementos maiores e traço foram analisados no Laboratório de Fluorescência de Raios X do Departamento de Geologia da Universidade Federal do Rio de Janeiro (UFRJ), em um espectrômetro de fluorescência de raio X Philips PW2400. A perda ao fogo foi obtida por meio do peso da amostra antes e depois de ser aquecida a $950^{\circ} \mathrm{C}$ por meia hora. A análise dos elementos maiores ocorreu a partir da fusão de $1,2 \mathrm{~g}$ de pó do material com tetraborato de lítio, enquanto os elementos traço envolveram $7 \mathrm{~g}$ do pó da amostra, que foi prensado com $1 \mathrm{~g}$ de cera aglutinante. $\mathrm{O}$ erro analítico estimado é: $\mathrm{Si}, \mathrm{Al}(<1 \%), \mathrm{Fe}, \mathrm{Mg}, \mathrm{Ca}(1-2 \%)$, Ti, Na, K $(3-5 \%)$, P e outros elementos traço $(\leq 6 \%)$.

A separação de $\mathrm{Sm}$ e Nd foi realizada no Laboratório de Geologia Isotópica da Universidade Federal do Pará (UFPA), conforme o método descrito por Oliveira et al. (2008). A análise isotópica foi realizada em modo estático, em um espectrômetro de massa de termoionização FINNIGAN modelo MAT 262, equipado com um sistema com sete coletores de Faraday. A determinação da composição isotópica do
$\mathrm{Nd}$ é realizada com a análise de dez blocos sucessivos de dez medidas isotópicas, permitindo a obtenção das razões ${ }^{142} \mathrm{Nd} /{ }^{144} \mathrm{Nd},{ }^{143} \mathrm{Nd} /{ }^{144} \mathrm{Nd},{ }^{145} \mathrm{Nd} / /{ }^{144} \mathrm{Nd},{ }^{146} \mathrm{Nd} /{ }^{144} \mathrm{Nd},{ }^{147} \mathrm{Sm} /{ }^{144} \mathrm{Nd}$ $\mathrm{e}^{150} \mathrm{Nd} /{ }^{144} \mathrm{Nd}$. A razão ${ }^{146} \mathrm{Nd} /{ }^{144} \mathrm{Nd}$ igual a 0,7219 é utilizada para a normalização das razões. Para o Sm, a composição isotópica é determinada com a análise de cinco blocos de dez medidas dos isótopos ${ }^{147} \mathrm{Sm},{ }^{149} \mathrm{Sm},{ }^{152} \mathrm{Sm},{ }^{154} \mathrm{Sm}$ e ${ }^{155} \mathrm{Gd}$.

As amostras para geocronologia (U-Pb em zircão) foram processadas no Laboratório Geológico de Preparação de Amostras da Universidade do Estado do Rio de Janeiro (LGPA/ UERJ). O método consistiu em lavagem, britagem, moagem, concentração dos minerais pesados por meio de bateia, secagem em estufa, retirada do material leve com bromofórmio e separação magnética com imã de mão. Para duas amostras de charnockito, utilizou-se a separação isomagnética no Frantz inicial com inclinação lateral de $10^{\circ}$, inclinação frontal de $2-5^{\circ}$ e amperagens de $0,2 \mathrm{~A}, 0,5 \mathrm{~A}, 0,75 \mathrm{~A}$ e $1,5 \mathrm{~A}$; Frantz final: inclinações laterais de $5^{\circ}, 3^{\circ}, 1^{\circ}$ e $0^{\circ}$ resultando em minerais magnéticos e não magnéticos ao campo magnético utilizado; inclinação frontal de $2-5^{\circ}$ com amperagem máxima $(1,5 \mathrm{~A})$. Para a amostra de gabronorito não foi utilizada a separação isomagnética no Frantz, uma vez que se trata de rocha com baixo potencial para zircão. Dessa maneira, o concentrado de minerais pesados foi levado diretamente ao iodeto de metileno, onde os cristais de apatita, principalmente, ficaram em suspensão e o zircão, dentre outros, decantou.

Os cristais de zircão, escolhidos independentemente de hábito para não padronizar as amostras, tiveram suas montagens realizadas no Laboratório de Preparação de Amostras do Departamento de Geologia da UFRJ.

As imagens de catodoluminescência foram produzidas no Centro de Tecnologia Mineral por meio do microscópio eletrônico de varredura LEO S440, operando a $30 \mathrm{kV}$.

As idades $\mathrm{U}-\mathrm{Pb}$ dos dois corpos foram obtidas pela análise de grãos de zircão por LA-ICPMS em um Thermo Finnigan Neptune multicollector do laboratório de geocronologia da Universidade de Brasília.

O processo Laser Ablation funciona como explicado por Bühn et al. (2009), com os seguintes parâmetros: $\mathrm{He}$, gás transportador na câmara de coleta com um fluxo $0,35-0,45 \mathrm{~L} / \mathrm{min}$; a frequência do laser foi de $7-10 \mathrm{~Hz}$, $30-36 \%$ da potência, com 0,5 a $1,2 \mathrm{~J} / \mathrm{cm}^{2}$ de energia; diâmetro do feixe de $30 \mu \mathrm{m}$, operando em velocidade de $1 \mu \mathrm{m} / \mathrm{sec}$. Com essa relação potência $\mathrm{x}$ velocidade, 1 minuto foi o tempo necessário para a coleta de material do zircão, com cerca de 40 ciclos por 1,049 segundo.

\section{CONTEXTO GEOLÓGICO}

Na região entre os estados de São Paulo e Minas Gerais, próximo às cidades de São Francisco Xavier, Campos do Jordão, São Bento do Sapucaí e Sapucaí-Mirim, ocorrem rochas de 
fácies granulito (média pressão) a anfibolito associadas à Faixa Brasília Meridional (Trouw et al., 2000, 2013; Negri, 2002; Negri e Oliveira, 2005; Campos Neto et al., 2011; Vinagre da Costa et al., 2014a, 2014b; Duffles et al., 2016). Essa faixa (Figura 1) tem sido interpretada como um segmento tectônico tangente à borda sul do Cráton do São Francisco produzida durante a colisão entre os paleocontinentes São Francisco e Paranapanema (Campos Neto, 2000; Campos Neto e Caby, 2000; Trouw et al., 2000; Valeriano et al., 2004, 2008; Campos Neto et al., 2004, 2010, 2011). Seus principais componentes são: o Grupo Andrelândia, representando parcialmente a margem passiva do paleocontinente São Francisco; e a
Nappe Socorro-Guaxupé, que corresponde à margem ativa do paleocontinente Paranapanema, em grande parte recoberto pelas rochas sedimentares e ígneas da Bacia do Paraná (Trouw et al., 2000; Janasi, 2002; Campos Neto et al., 2010, 2011). A Faixa Brasília Meridional é dominada por um trend estrutural NNW-SSE, sendo subdividida em nappes com empilhamento tectônico vergente para ENE. O metamorfismo das nappes aumenta para W (Trouw et al., 2000) a partir do Cráton do São Francisco, em direção à sutura com o paleocontinente Paranapanema. No contato basal da sutura, esse metamorfismo chega à fácies granulito de alta pressão com ocorrência local de eclogitos reliquiares reequilibrados nas fácies granulito (raro)
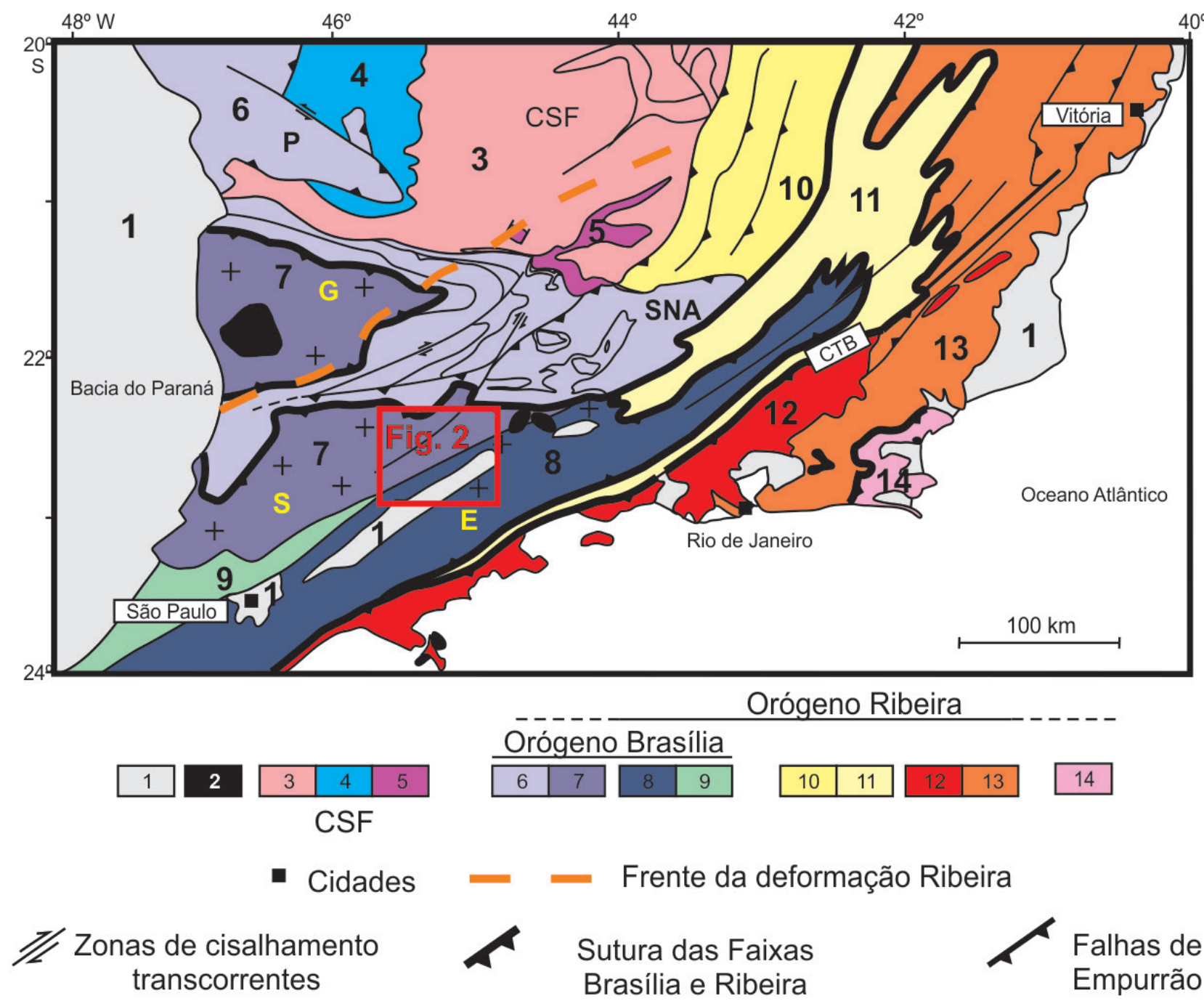

Figura 1. Mapa tectônico segundo Trouw et al. (2013); (1) bacias fanerozoicas; (2) plutons alcalinos cretácicos/ cenozoicos; (3 - 5) cráton do São Francisco e antepaís: (3) embasamento arqueano/paleoproterozoico; (4) cobertura (Grupo Bambuí); (5) cobertura (rochas metassedimentares autóctones e alóctones); (6 - 9) Faixa Brasília: (6) Sistema de Nappes Andrelândia (SNA) e Nappe de Passos (P); (7) Nappe Socorro (S)-Guaxupé (G); (8) Terreno Embu-Paraíba do Sul (E); (9) Terreno Apiaí; (10 - 14) Faixa Ribeira: (10) Domínio Externo; (11) Domínio Juiz de Fora; (12) Arco Rio Negro (Terreno Oriental); (13) Terreno Oriental; (14) Terreno Cabo Frio. Observar a zona de interferência entre as faixas Brasília e Ribeira, limitada pela linha tracejada que representa a frente da Faixa Ribeira. 
e anfibolito. Já na Nappe Socorro-Guaxupé, bloco continental cavalgante Paranapanema, o metamorfismo diminui em direção a W. Idades U-Pb em zircão e monazita oriundas de rochas da base da Nappe Socorro e de rochas em porções crustais intermediárias tanto na Nappe Socorro como na Sequência de Nappes Andrelândia apontam um estágio colisional entre 630 e $605 \mathrm{Ma}$, colisão essa antecedida por um magmatismo de arco entre 680 e $630 \mathrm{Ma}$ (Basei et al., 1995; Hackspacher et al., 2003; Peternel et al., 2005; Campos Neto et al., 2004, 2011; Trouw, 2008; Reno et al., 2009, 2010, 2012; Vinagre da Costa et al., 2014a).

Uma segunda colisão continental produziu, a sul da Faixa Brasília Meridional, a Faixa Ribeira Central (Heilbron et al., 2004, 2008; Figura 1). Essas duas faixas móveis estariam separadas pela Zona de Cisalhamento Jundiuvira/Buquira (Campos Neto, 2000), definida a NE da cidade de São Paulo. No entanto, Trouw et al. (2013) reinterpretaram o contato entre as faixas móveis Brasília Meridional e Ribeira Central, expandindo a primeira faixa mais para sul, sugerindo que o Terreno Embu pode fazer parte da Nappe Socorro-Guaxupé (Figura 1). Entretanto, nessa concepção a Faixa Ribeira Central se sobrepõe a essa nappe numa zona de interferência. Idades $\mathrm{U}-\mathrm{Pb}$ em zircão e monazita obtidas em rochas derivadas de fusão crustal sin-colisional mostram que esse evento termotectônico se deu entre 590 e $560 \mathrm{Ma}$ (Heilbron et al., 2003, 2004, 2008; Janasi et al., 2003).

\section{GEOLOGIA LOCAL}

O Gabronorito Ribeirão do Paiol e o Charnockito São Francisco Xavier correspondem a corpos magmáticos encaixados nos metagranitoides do Batólito Serra da Água Limpa - BSAL (Trouw et al., 2013; Vinagre da Costa et al., 2014a, 2014b), que possuem idades de cristalização (U-Pb em zircão) variando entre 670 e $630 \mathrm{Ma}$ (Vinagre da Costa et al., 2014a). O BSAL, juntamente com outros metagranitoides existentes nessa região, é interpretado como parte do arco magmático instalado no paleocontinente Paranapanema durante a Orogênese Brasiliana (Trouw et al., 2013; Vinagre da Costa et al., 2014a, 2014b).

\section{Gabronorito Ribeirão do Paiol}

Essa unidade, até então não descrita na literatura, está exposta em três pequenos corpos, além de diques centimétricos a métricos, localizados a SW do município de Sapucaí-Mirim, Minas Gerais (Figura 2). Esses corpos ocorrem com forma alongada e alinhados segundo a direção NE-SW, estando encaixados em metagranitoides do BSAL e contendo xenólitos da sua encaixante (Figura 3A).

O Gabronorito Ribeirão do Paiol é isotrópico e apresenta textura inequigranular seriada hipidiomórfica a xenomórfica.
Sua granulação varia de fina a média e o índice de cor, entre $44 \mathrm{e}$ 53\% (Tabela 1; Figura 3B). A rocha é composta essencialmente de plagioclásio, clino e ortopiroxênio, enquanto apatita, minerais opacos e zircão, K-feldspato e quartzo são as fases acessórias. Além desses, hornblenda, biotita, mica branca e alguns cristais de minerais opacos ocorrem como fases secundárias.

O plagioclásio, subédrico a anédrico, tem contatos retos e sinuosos, geminação polissintética bem definida e zoneamento composicional. Como inclusões ocorrem clino e ortopiroxênios, apatita e zircão, compondo texturas poiquilíticas quando totalmente inclusos no grão hospedeiro. $\mathrm{O}$ clinopiroxênio e o ortopiroxênio (Figuras 3C, 3D, 3E e 3F) são subédricos e anédricos (Figura 3C), ocorrendo com granulação menor que a do plagioclásio, localmente definindo textura intergranular (Figura 3D). O clinopiroxênio é incolor, às vezes com um leve pleocroísmo esverdeado. Aparenta ter um zoneamento composicional, já que comumente as porções centrais dos cristais ocorrem substituídas por hornblenda e biotita, o que é menos frequente nas bordas (Figuras 3E e 3F). Como inclusões ocorrem apatita e, raro, zircão. O ortopiroxênio é caracterizado por um leve pleocroísmo variando de incolor a rosa claro e comumente mostra feições típicas de substituição nos domínios de borda por minerais opacos. Como inclusões ocorrem apatita, minerais opacos primários e, raro, zircão. O K-feldspato, raro e anédrico, ocupa os interstícios entre os cristais de plagioclásio e piroxênios, e seus contatos com o plagioclásio são caracterizados por franjas mirmequíticas. O quartzo, também raro, é sempre anédrico por ocupar os interstícios entre os demais minerais. Tem extinção levemente ondulante e inclusões da maior parte da associação mineralógica da rocha. Apatita, zircão e minerais opacos primários variam de subédricos a anédricos e ocorrem dispersos na rocha ou na forma de inclusões.

\section{Charnockito São Francisco Xavier}

O Charnockito São Francisco Xavier (Sadowski e Carneiro, 1974; Cavalcante et al., 1979; Oliveira et al., 1983; Negri, 2002; Negri e Oliveira, 2005) aflora nas proximidades do distrito de São Francisco Xavier, leste do estado de São Paulo e próximo à divisa com o estado de Minas Gerais, no extremo sul do lobo Socorro da Nappe Socorro-Guaxupé. Negri (2002) e Negri e Oliveira (2005) designaram esse corpo como Maciço Quartzo Mangerito-Charnockito-Monzogranito São Francisco Xavier. Segundo esses autores, é composto predominantemente de quartzo mangeritos, charnockitos e, localmente, mangeritos e quartzo monzonitos com granulação média a grossa, textura inequigranular porfirítica e feldspatos esverdeados a verde acinzentados.

O Charnockito São Francisco Xavier é representado por três corpos com formas irregulares, um com aproximadamente $13 \mathrm{~km}^{2}$ e os outros dois com cerca de $1 \mathrm{~km}^{2}$, todos localizados nas proximidades de São Francisco Xavier 
(Figura 2), cujas rochas encaixantes correspondem ao BSAL e um granada-cordierita-sillimanita paragnaisse.

O charnockito apresenta textura ígnea, isotrópica, equigranular (Figura 4A) a inequigranular seriada e porfirítica (Figura 4B), com índice de cor entre 16 e 21\% (Tabela 1). Quando inequigranular, os fenocristais são de microclínio e plagioclásio com no máximo $5 \mathrm{~cm}$ de comprimento. A matriz tem granulação média a grossa e é composta essencialmente de plagioclásio, microclínio, ortoclásio, quartzo, clinopiroxênio (Figura 4C), ortopiroxênio, hornblenda e biotita. Minerais opacos, apatita e zircão são as fases acessórias. Alguns cristais de hornblenda, biotita e minerais opacos representam fases secundárias (Figuras 4C e 4D).

O plagioclásio é normalmente anédrico e raramente subédrico, tem contatos sinuosos, extinção ondulante incipiente e geminação polissintética. Quando em contato com ortoclásio, exibe franjas mirmequíticas. São comuns inclusões submilimétricas de apatita, zircão, clino e ortopiroxênio, compondo localmente textura poiquilítica. $\mathrm{O}$ ortoclásio varia de anédrico a subédrico, possui contatos sinuosos com os demais minerais essenciais da rocha e encontra-se com incipiente extinção ondulante. Pontualmente apresenta lamelas pertíticas e inclusões de apatita e zircão, principalmente nos domínios de borda. O quartzo ocupa os interstícios entre os demais minerais em função de sua cristalização tardia; normalmente tem inclusões de feldspatos, zircão, apatita e fases opacas. Os grãos de piroxênios variam de anédricos a subédricos e exibem contatos sinuosos e retilíneos com os demais minerais essenciais. O clinopiroxênio (Figura 4C) é levemente esverdeado e por vezes ocorre associado à hornblenda verde oliva e à biotita. $\mathrm{O}$ ortopiroxênio tem cor rosada, às vezes levemente pleocróica (de rosa a rosa

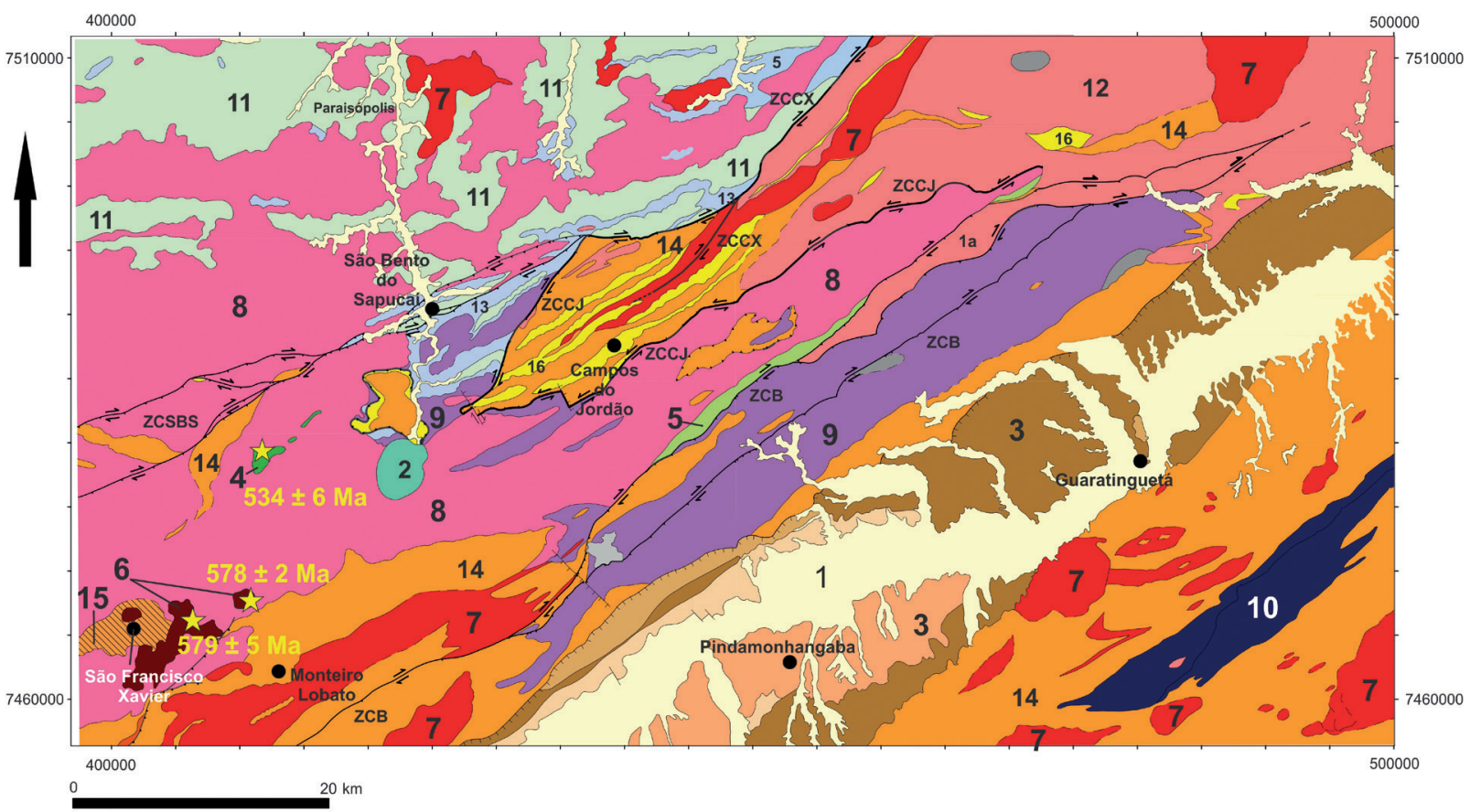

$20 \mathrm{~km}$

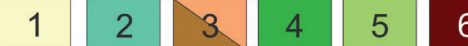

6

Nappe Socorro e Terreno Embu

\section{Zona de cisalhamento} transcorrente destral

\begin{tabular}{|l|l|l|l|l|l|l|l|l|}
\hline 8 & 9 & 10 & 11 & 12 & 13 & 14 & 15 & 16 \\
\hline
\end{tabular}

\section{- Cidade $\checkmark$ Ponto com análise geocronológica U-Pb}

Figura 2. Mapa geológico da área estudada entre as cidades de São Francisco Xavier, Paraisópolis e Guaratinguetá (compilado e simplificado a partir de Peternel et al., 2014 e Trouw et al., 2014). (1) aluviões recentes; (2) Maciço Alcalino Cretácico Ponte Nova; (3) Bacia de Taubaté; (4) Gabronorito Ribeirão do Paiol; (5) Formação Pico do Itapeva; (6) Charnockito São Francisco Xavier; (7) granitos e (meta)granitos com idade entre 610 e 570 Ma; (8) Batólito Serra da Água Limpa; (9) Complexo Gnáissico Pedra do Baú; (10) Batólito Serra do Quebra-Cangalha; (11) Complexo Gnáissico Serra de São Bernardo; Terreno Embu: (12) paragnaisse (metavaque); (13) paragnaisse (metapelito); (14) biotita xisto (metapelito); (15) paragnaisse (metapelito) com cordierita; (16) quartzito. ZCSBS: Zona de Cisalhamento São Bento do Sapucaí; ZCB: Zona de Cisalhamento Buquira; ZCCJ: Zona de Cisalhamento Campos do Jordão; ZCCX: Zona de Cisalhamento Caxambu; ZCMF: Zona de Cisalhamento Maria da Fé. 
claro), e normalmente ocorre associado a fases opacas nos domínios de borda. Os grãos de apatita, zircão e minerais opacos primários ocorrem dispersos na rocha ou inclusos em praticamente todos os outros minerais.
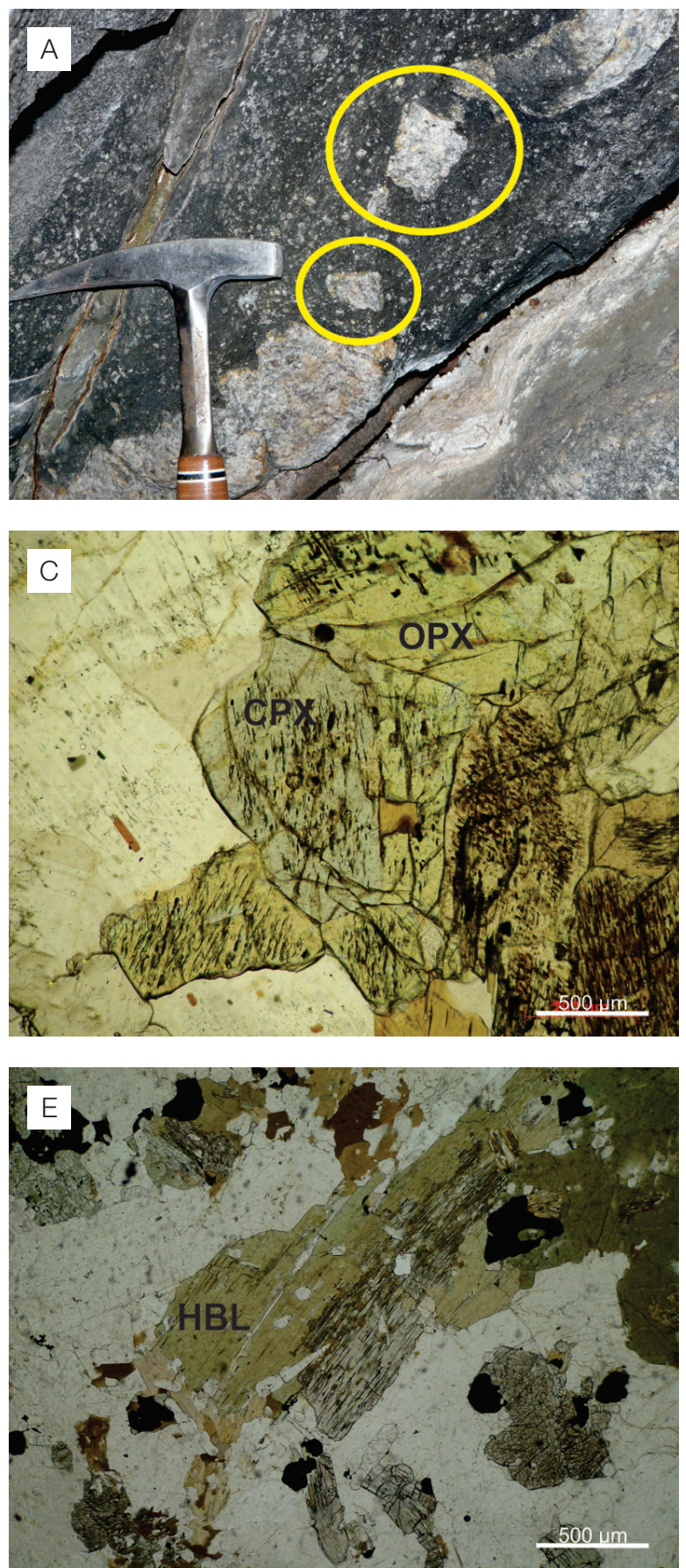

Por meio do geotermômetro baseado em saturação de zircônio em rocha total (Watson e Harrison, 1983 adaptado por Miller et al., 2003), foi obtida uma temperatura de aproximadamente $880^{\circ} \mathrm{C}$ para a
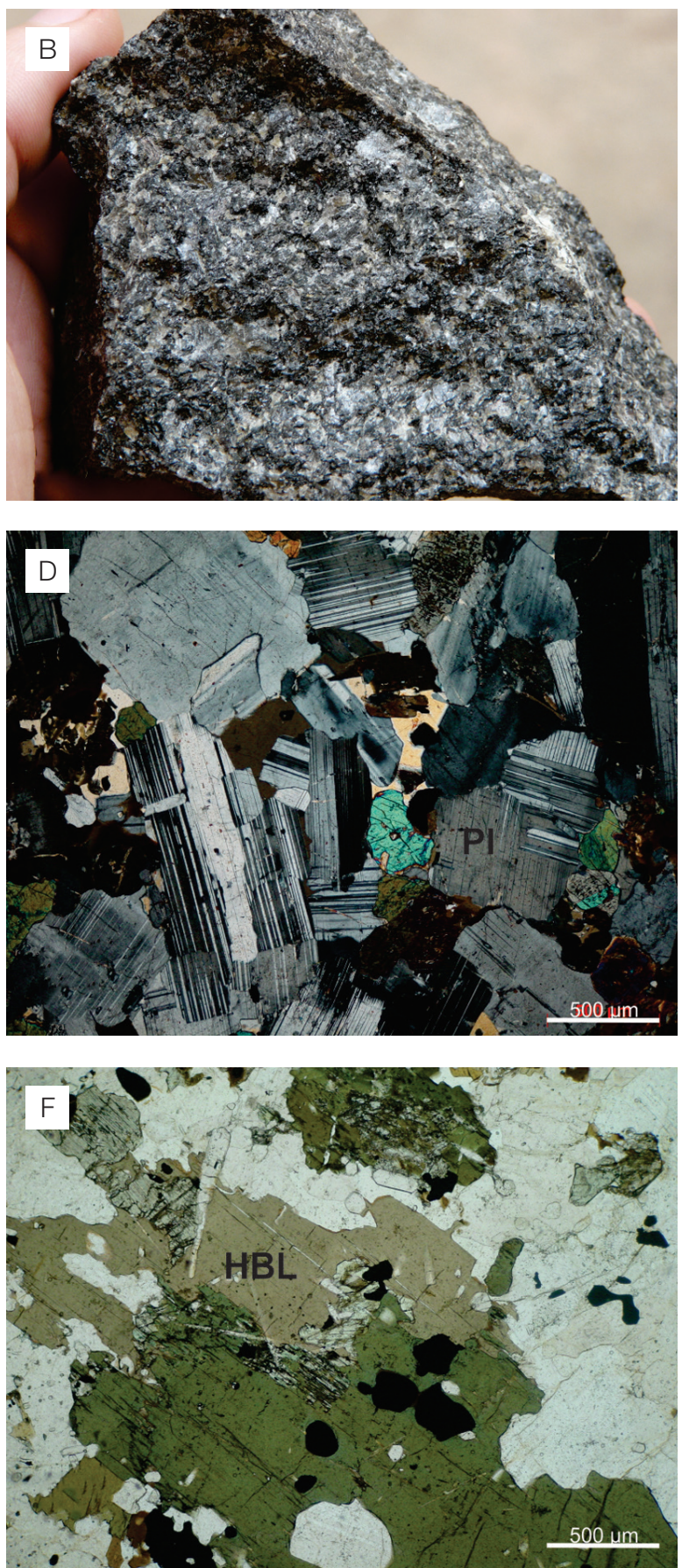

Figura 3. Gabronorito Ribeirão do Paiol. (A) Xenólitos de metagranitoide (círculos amarelos) interpretados como correlatos ao Batólito Serra da Água Limpa; (B) aspecto megascópico de amostra de mão; (C) aspecto microscópico mostrando cristais de clino e ortopiroxênio (polarizadores //); (D) trama equigranular; notar o aspecto intersticial dos piroxênios (polarizadores X); (E) textura de substituição de clinopiroxênio por hornblenda (polarizadores //); (F) detalhe de cristais de hornblenda originados a partir de desequilíbrio de piroxênio (polarizadores //). 
Tabela 1. Composição modal de amostras do Gabronorito Ribeirão do Paiol e do Charnockito São Francisco Xavier. Contagem de 800 pontos por lâmina.

\begin{tabular}{|c|c|c|c|c|c|c|c|c|c|}
\hline & \multicolumn{4}{|c|}{ Gabronorito } & \multicolumn{5}{|c|}{ Charnockito } \\
\hline & MLR 292 & MLR 398 & MLR 35 & MLR 30a & RDML 60 & MLR 138 & MLR 242 & MLR 244 & MLR 432 \\
\hline Quartzo & 1 & 2 & $\operatorname{tr}$ & 1 & 24 & 34 & 17 & 22 & 17 \\
\hline K-feldspato & 1 & 1 & $\operatorname{tr}$ & 1 & 30 & 29 & 26 & 25 & 19 \\
\hline Plagioclásio & 45 & 51 & 56 & 47 & 26 & 17 & 40 & 37 & 43 \\
\hline Biotita & 15 & 22 & 12 & 20 & 9 & 11 & 7 & 5 & 10 \\
\hline Hornblenda & 2 & 1 & - & 1 & 5 & 5 & 6 & 1 & - \\
\hline Clinopiroxênio & 25 & 16 & 15 & 20 & 3 & - & 3 & 5 & 5 \\
\hline Ortopiroxênio & 5 & 4 & 13 & 5 & 2 & - & 1 & 4 & 4 \\
\hline Epidoto & - & - & - & - & - & 1 & - & - & - \\
\hline Titanita & - & - & - & - & - & 1 & - & - & - \\
\hline $\begin{array}{l}\text { Minerais } \\
\text { opacos }\end{array}$ & 6 & 3 & 4 & 5 & 1 & 2 & $\operatorname{tr}$ & 1 & 2 \\
\hline Zircão & $\operatorname{tr}$ & $\operatorname{tr}$ & $\operatorname{tr}$ & $\operatorname{tr}$ & tr & $\operatorname{tr}$ & $\operatorname{tr}$ & $\operatorname{tr}$ & $\operatorname{tr}$ \\
\hline Apatita & $\operatorname{tr}$ & $\mathrm{tr}$ & $\mathrm{tr}$ & $\mathrm{tr}$ & $\mathrm{tr}$ & $\mathrm{tr}$ & $\mathrm{tr}$ & $\mathrm{tr}$ & $\mathrm{tr}$ \\
\hline
\end{tabular}
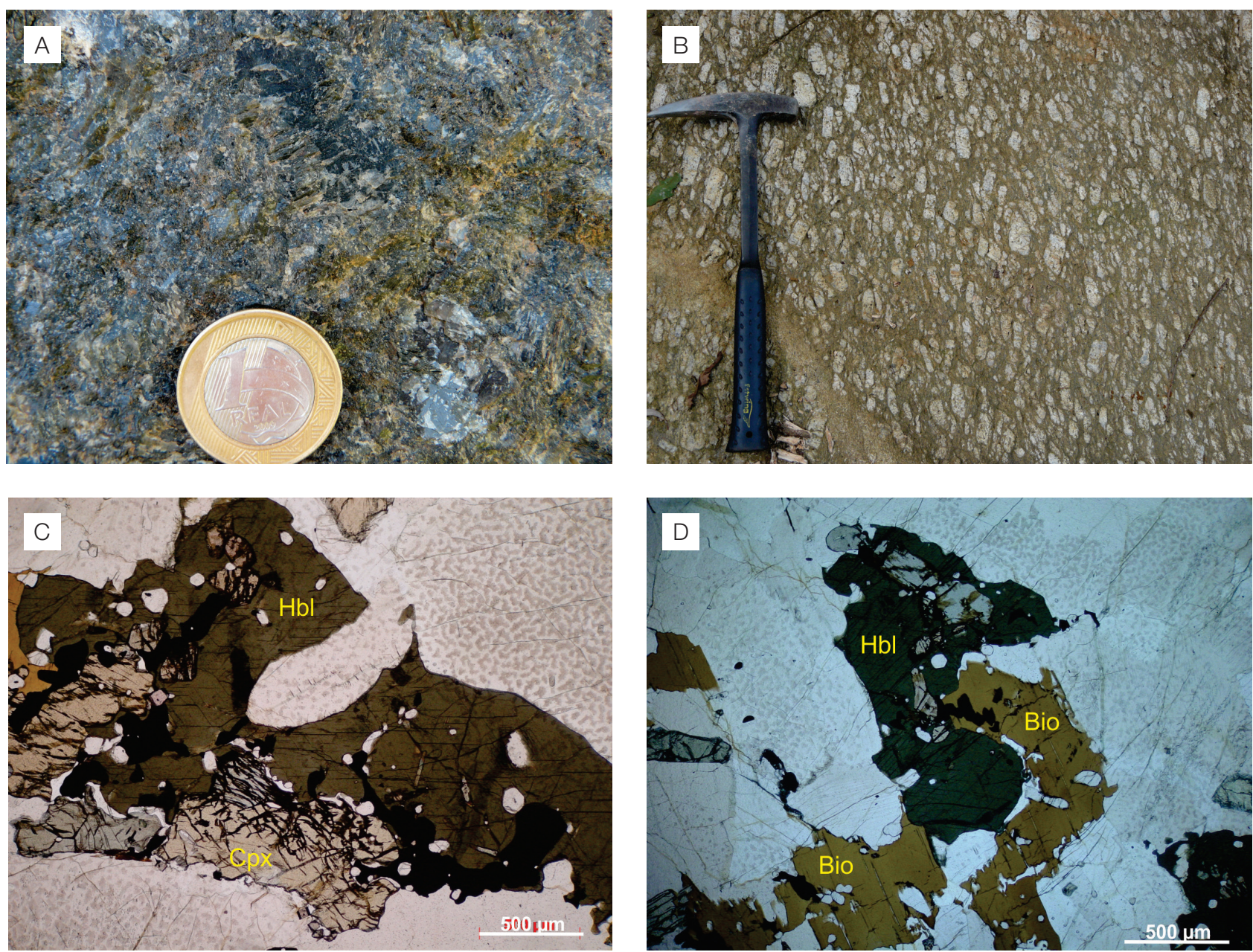

Figura 4. Charnockito São Francisco Xavier. (A) Textura equigranular em amostra de mão; (B) textura inequigranular porfirítica; (C) textura de substituição onde a hornblenda se desenvolve a partir do clinopiroxênio (polarizadores //); (D) relação de contato irregular entre cristais de hornblenda e biotita (polarizadores //). 
cristalização do charnockito, o que é coerente com sua composição mineralógica.

\section{GEOCRONOLOGIA (U-PB EM ZIRCÃO)}

\section{Gabronorito Ribeirão do Paiol}

O afloramento selecionado para datação situa-se nas proximidades do bairro Cabral, no município de Sapucaí-Mirim, estado de Minas Gerais (coordenadas: 411700 / 7479351). É representado por rocha isotrópica com textura equigranular média a grossa (Figura 3B). Os cristais de zircão são raros, incolores e com muitas fraturas. Possuem hábito predominantemente prismático com razão comprimento/ largura de (3:1), com terminações truncadas, tendo alguns cristais terminações piramidais.

Imagens de catodoluminescência mostram que alguns cristais possuem zoneamento incipiente (Figura 5, Z9 e
Z28), sendo que a maioria deles não apresenta contraste bem definido entre centro e borda.

Foram realizadas 22 análises em cristais de zircão, e os dados concordantes (Tabela 2) variam no intervalo entre 600 e $526 \mathrm{Ma}$. As elevadas razões Th/U apontam a natureza ígnea dos cristais estudados. Os núcleos dos cristais $\mathrm{Z} 9, \mathrm{Z} 27$ e Z14 apresentam idades $\mathrm{Pb}^{206} / \mathrm{U}^{238}$ concordantes de $546 \pm 4,529 \pm 8$ e $528 \pm 5 \mathrm{Ma}$, respectivamente. O grão Z28 apresenta idades concordantes distintas no núcleo e na borda: $576 \pm 10$ e $542 \pm 7 \mathrm{Ma}$, respectivamente (Figura 5).

Dois cristais apresentaram idades de aproximadamente $600 \mathrm{Ma}$, quatro entre 585 e $575 \mathrm{Ma}$ e cinco entre 550 e $525 \mathrm{Ma}$.

A Figura 6 mostra um gráfico concórdia com idade de $534 \pm 6 \mathrm{Ma}$, dado por 8 cristais, todos analisados nas suas porções centrais.

Como pode ser observado na Tabela 2 , as idades ígneas mais jovens estão contidas no intervalo entre 550 e $520 \mathrm{Ma}$,

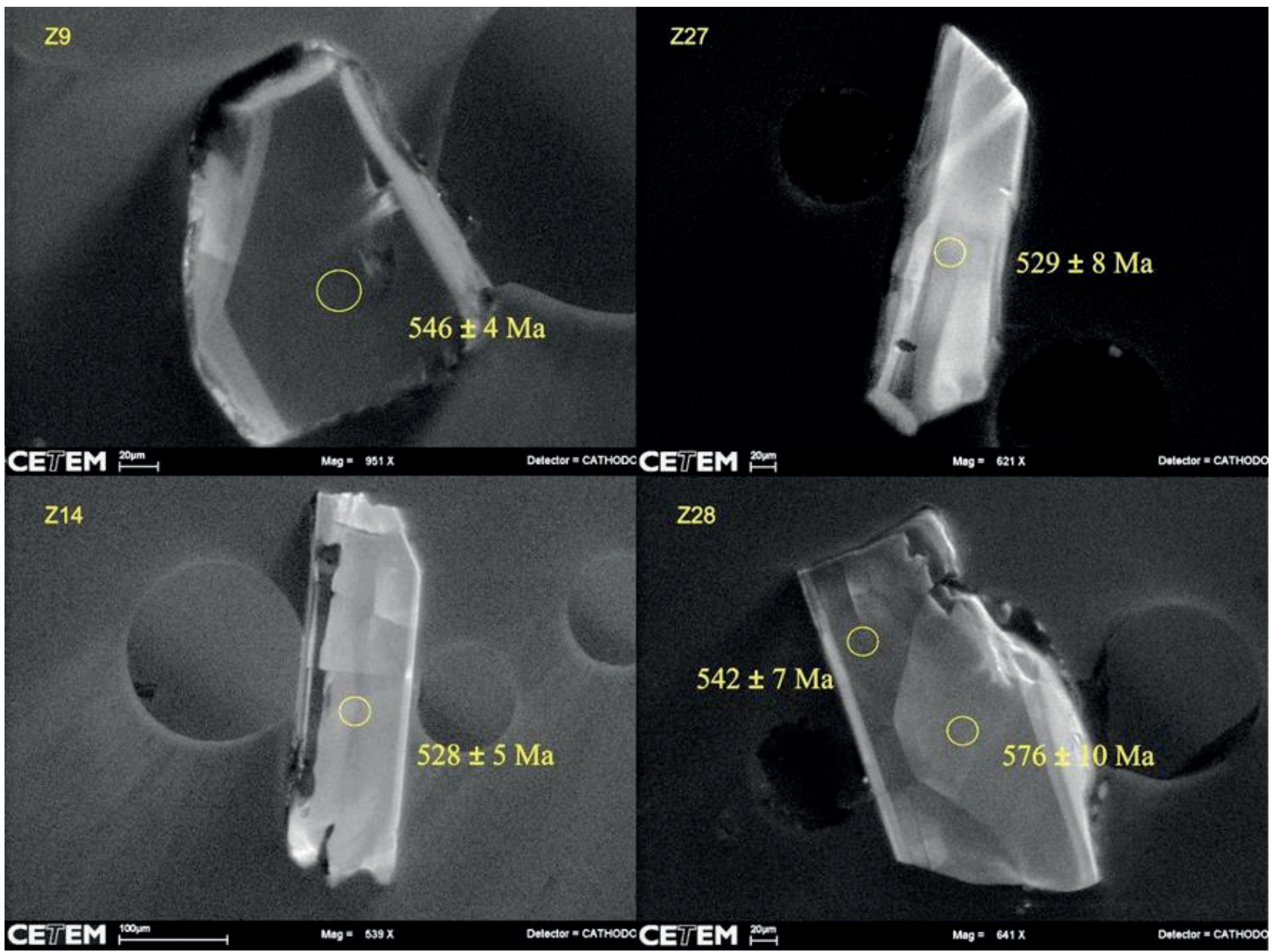

Figura 5. Cristais de zircão do Gabronorito Ribeirão do Paiol. Os círculos amarelos nas imagens de catodoluminescência representam as áreas analisadas nos grãos. 
Tabela 2. Resumo das análises isotópicas U-Pb do Gabronorito Ribeirão do Paiol (MLR 292), em que a coluna referente às idades $\mathrm{Pb}^{206} / \mathrm{U}^{238}$ está disposta em ordem decrescente.

\begin{tabular}{|c|c|c|c|c|c|c|c|c|c|c|c|c|c|c|c|c|c|}
\hline nálises & $\begin{array}{c}{ }^{206} \mathrm{~Pb} \\
(\%)\end{array}$ & $\begin{array}{l}\text { Th } \\
\mathrm{U}\end{array}$ & $\begin{array}{c}{ }^{206} \mathrm{~Pb} \\
{ }^{204} \mathrm{~Pb} \\
(\%)\end{array}$ & $\begin{array}{c}{ }^{207} \mathrm{~Pb} \\
{ }^{206} \mathrm{~Pb} \\
(\%)\end{array}$ & $\begin{array}{c}1 \mathrm{~s} \\
(\%)\end{array}$ & $\begin{array}{c}{ }^{207} \mathrm{~Pb} \\
{ }^{235} \mathrm{U} \\
(\%)\end{array}$ & $\begin{array}{c}1 \mathrm{~s} \\
(\%)\end{array}$ & $\begin{array}{c}{ }^{206} \mathrm{~Pb} \\
{ }^{238} \mathrm{U} \\
(\%)\end{array}$ & $\begin{array}{c}1 \mathrm{~s} \\
(\%)\end{array}$ & $\begin{array}{l}{ }^{207} \mathrm{~Pb} \\
{ }^{206} \mathrm{~Pb}\end{array}$ & $1 \mathrm{~s}$ & $\begin{array}{c}{ }^{207} \mathrm{~Pb} \\
{ }^{235} \mathrm{U}\end{array}$ & $1 \mathrm{~s}$ & $\begin{array}{c}{ }^{206} \mathrm{~Pb} \\
{ }^{238} \mathrm{U}\end{array}$ & $1 \mathrm{~s}$ & $\mathrm{Rh}$ & $\begin{array}{c}\text { Conc } \\
(\%)\end{array}$ \\
\hline 30 & 03 & 4 & 57172 & 0,0591 & 0,5 & 0,7959 & 1,6 & 0976 & 5 & 1 & 0,2 & 5 & 7,0 & 0 & 8,5 & 95 & 104 \\
\hline 19 & 04 & 30 & 2112 & D594 & 1,2 &, 7976 & ,8 & 0973 & 1,4 & 3,0 & 25,5 & 5,5 & 3,3 & 98,8 & 8,1 & 92 & 02 \\
\hline 20 & 01 & 1.56 & 213286 & 0,0589 & 0,3 & 0,7750 & ,9 & 0,0954 & 0,9 & 84,8 & 6,0 & 582,6 & 4,1 & 587,2 & 4,9 & 95 & 03 \\
\hline 26 & 05 & 98 & 37709 & 0,0590 & 1,4 & 0,7745 & ,8 & 0951 & 1,2 & 568,5 & 30,1 & 582,3 & 8,2 & 585,9 & 6,9 & 86 & 103 \\
\hline 41 & 10 & 99 & 7779 & 0587 & 0,8 & 0,7557 & 1,0 & 0934 & 1,8 & 4,6 & 16,9 & 571,5 & 8,7 & 575,8 & 10,1 & 0,92 & 03 \\
\hline 28 & D7 & 6 & 040 & 592 & 1,3 & 28 &, 4 & p934 & 2,0 &, 7 & 29,2 & 575,6 & 10,5 & 575,6 & 10,8 & 0,94 & 100 \\
\hline 42 & 04 & 2 & 0258 & 0589 & 1,0 & 0,7461 &, 5 & 0919 & 1,2 &, 2 & 21,5 & 566,0 & 6,7 & 566,6 & 6,5 & 0,91 & 100 \\
\hline 39 & 14 & ,21 & 14452 & 0,0580 & 0,8 & 0,7097 & ,8 & ,0887 & 1,6 & 530,4 & 17,8 & 544,6 & 7,4 & 547,9 & 8,2 & 0,88 & 103 \\
\hline 79 & 0,02 & 27 & 109656 & 0,0586 & 0,4 & 0,7144 & 1,9 & 0,0884 & 0,8 & 552,3 & 8,7 & 547,3 & 3,8 & 546,1 & 4,3 & 0,88 & 99 \\
\hline 37 & 0,09 & 05 & 9418 & 0,0579 & 0,9 & 0,7018 & , & 0,0879 & 1,1 & 526,1 & 20,6 & 539,8 & 5,9 & 543,1 & 5,5 & 0,73 & 103 \\
\hline 14 & 0,13 & 82 & 3924 & 0576 & 1,0 & 0,6777 & ,4 & 0,0853 & 1,0 & , 3 & 22,3 & 525,4 & 5,7 & 527,7 & 4,9 & 0,67 & 102 \\
\hline 36 & 0,06 & 0,97 & 23202 & 0,0584 & 0,9 & 0,6846 & 1,3 & 0,0850 & 1,0 & 544,9 & 20,0 & 529,6 & 5,5 & 526,0 & 4,8 & 0,70 & 96 \\
\hline
\end{tabular}
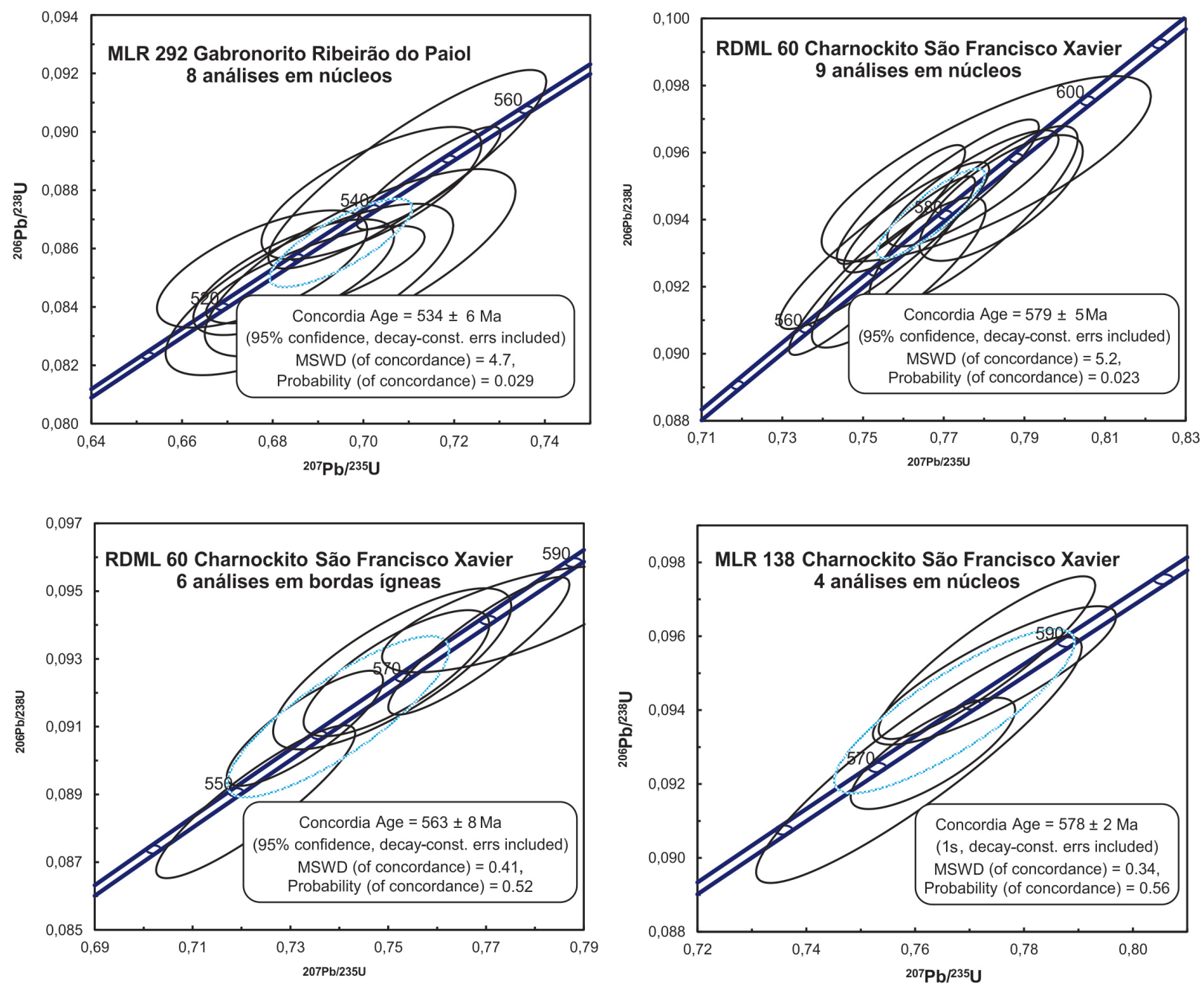

Figura 6. Gráficos concórdia para uma amostra do Gabronorito Ribeirão do Paiol (MLR 292) e duas do Charnockito São Francisco Xavier (RDML 60 e MLR 138). 
justificando a interpretação de que a idade de $534 \pm 6 \mathrm{Ma}$ corresponde à cristalização da rocha. As idades mais antigas são consideradas como tendo sido obtidas em cristais herdados.

\section{Charnockito São Francisco Xavier}

Foram datadas amostras de dois afloramentos. O primeiro (RDML 60, Figura 4A), localizado nas proximidades do bairro Cateto, 4 km a leste de São Francisco Xavier (coordenadas: 405992 / 7465834), é caracterizado pela textura equigranular isotrópica com granulação grossa.

O segundo (MLR 138, Figura 4B), situado nas proximidades da Fazenda Rio Manso, $6 \mathrm{~km}$ a norte de Monteiro Lobato (coordenadas: 410228 / 7467883), é uma rocha com textura inequigranular porfirítica, onde os fenocristais tabulares de microclínio alcançam até $5 \mathrm{~cm}$ de comprimento. Esse afloramento apresenta foliação tectônica produto de uma zona de cisalhamento local.

\section{$R D M L 60$}

Os cristais de zircão são incolores, raramente amarelados, com poucas fraturas e inclusões e em geral possuem forma prismática (3:1) com terminações piramidais. As imagens por catodoluminescência mostram que os grãos possuem marcante zoneamento ígneo com os núcleos tendendo a ser mais homogêneos (Figura 7).

No total, foram obtidas 47 análises com concordância entre 95 e 105\% em 31 cristais de zircão (Tabela 3). Por meio de gráficos concórdia, foram obtidas duas idades: $579 \pm 5 \mathrm{Ma}$ (Figura 6; 9 análises concordantes em núcleos) e $562 \pm 8$ Ma (Figura 6; 6 análises concordantes em bordas).

A idade de $579 \pm 5$ Ma (Figura 6) representa a maioria das análises concordantes obtidas nos núcleos dos cristais, por isso é interpretada como correspondente à cristalização da rocha. Essa idade é similar à determinada por Negri (2002), de $590-585 \mathrm{Ma}$, para rochas do mesmo corpo.

Idades concordantes mais antigas, entre 620 e $600 \mathrm{Ma}$, determinadas tanto em núcleos como em bordas, são atribuídas à herança da encaixante, uma vez que nessas rochas hospedeiras, durante esse intervalo, houve importante fase de crescimento de zircão metamórfico (Trouw et al., 2013; Vinagre da Costa et al., 2014a; Duffles et al., 2016).

Como as bordas não parecem ter origem metamórfica (razões Th-U variando entre 0,3 e 0,6), mas apenas fazem parte do zoneamento magmático dos cristais de zircão, a idade mais jovem determinada em bordas, $562 \pm 8 \mathrm{Ma}$ (Figura 6), é interpretada como de uma fase tardia de formação dos cristais magmáticos.

\section{MLR 138}

Os cristais de zircão são amarelados, bastante fraturados e com moderada quantidade de inclusões. Têm em geral hábito prismático (3:1), com terminações piramidais. As imagens de catodoluminescência mostram cristais bem estruturados internamente, desde a porção mais central até os domínios de borda (Figura 7). São raras as bordas homogêneas, interpretadas como metamórficas.

No total foram realizadas 30 análises em 26 grãos de zircão. A Tabela 4 apresenta os resultados concordantes.

O gráfico concórdia da Figura 6 mostra uma idade de $578 \pm 2 \mathrm{Ma}$, obtida por meio de quatro análises em núcleos.

\section{Sm-Nd EM ROCHA TOTAL}

Das três amostras analisadas pelo método U-Pb em zircão, duas tiveram suas razões $\mathrm{Sm}-\mathrm{Nd}$ (rocha total) obtidas: uma do Gabronorito Ribeirão do Paiol (MLR 292) e outra do Charnockito São Francisco Xavier (RDML 60).

Comparando os valores dos resultados $\mathrm{T}_{\mathrm{DM}}$ da amostra do Charnockito São Francisco Xavier com a do Gabronorito Ribeirão do Paiol (Tabela 5), percebe-se uma provável diferença na origem dos seus magmas formadores, uma vez que as idades $\mathrm{T}_{\mathrm{DM}}$ são bem distintas: 2,02 e 1,44 Ga, respectivamente. Idades $T_{D M}$ mesoproterozoicas na Faixa Ribeira têm sido consideradas como resultado de mistura de fontes paleo e neoproterozoicas (p.e. Tupinambá et al., 2012, Bento dos Santos et al., 2011). Os dois corpos analisados exibem valores negativos de $\varepsilon_{\mathrm{Nd}}(t),-7,32$ para o gabronorito e -12,41 para o charnockito (Tabela 3), apontando para a participação de material crustal na formação do magma que originou o charnockito. $\mathrm{O}$ valor obtido para o gabronorito indica contaminação crustal na história evolutiva do magma parental, de provável natureza mantélica.

\section{CARACTERIZAÇÃO LITOGEOQUÍMICA PRELIMINAR}

Foram analisadas 8 amostras (Tabela 6), sendo seis do Charnockito São Francisco Xavier e duas do Gabronorito Ribeirão do Paiol. A pouca quantidade de amostras do gabronorito se deve aos raros afloramentos de rocha inalterada, cuja amostragem permitiu análise química.

Com relação aos teores de $\mathrm{SiO}_{2}$, as amostras do gabronorito são básicas, variando entre 45 e $49 \%$, enquanto as do charnockito são intermediárias, com teores entre 59 e $64 \%$.

Nos diagramas AFM e TAS da Figura 8 fica evidente o maior enriquecimento em álcalis do Charnockito São Francisco Xavier, contrastando nitidamente com o Gabronorito Ribeirão do Paiol, que possui conteúdos de $\mathrm{MgO}$ muito mais 


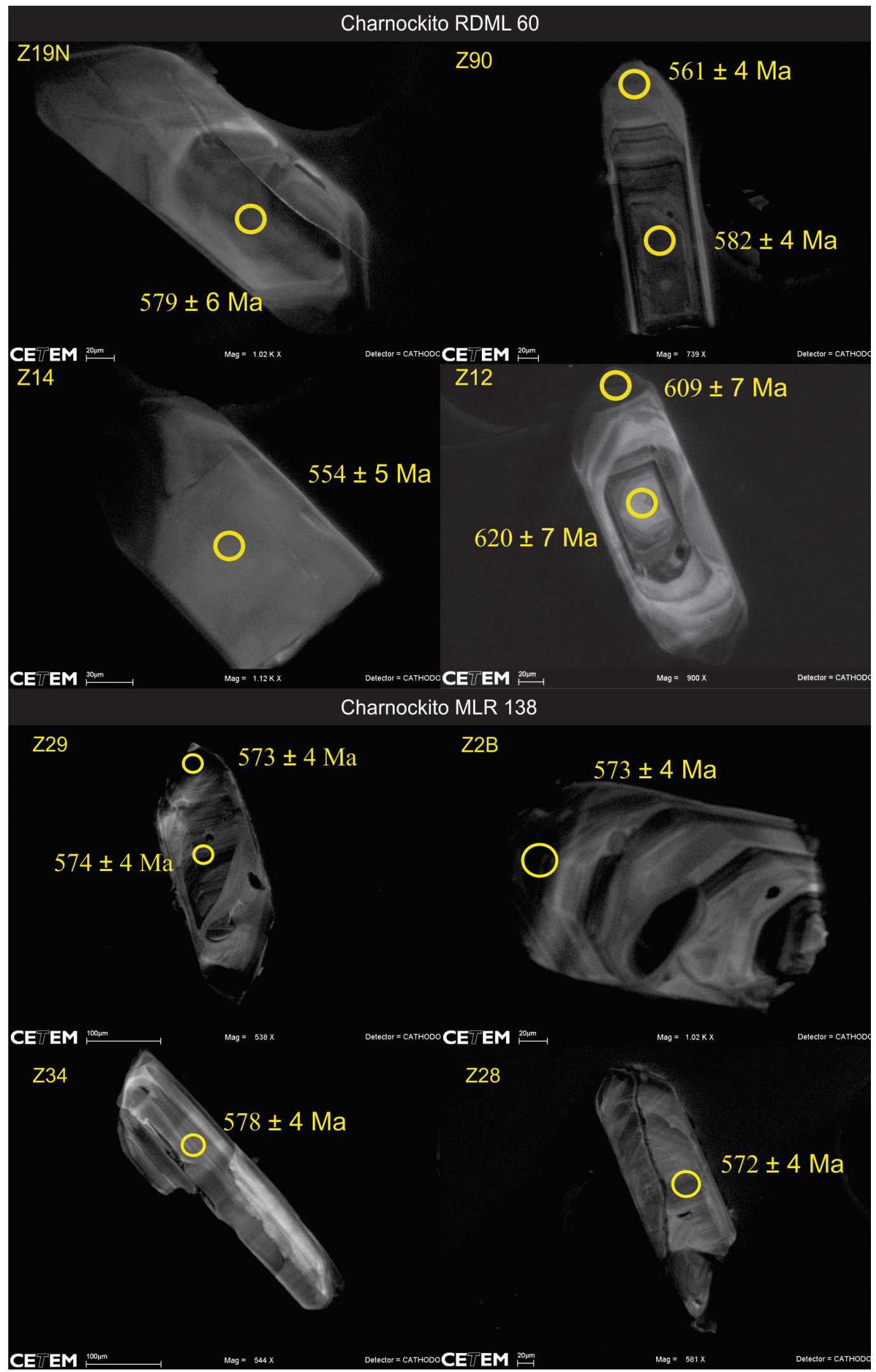

Figura 7. Cristais de zircão do Charnockito São Francisco Xavier. Os círculos amarelos nas imagens de catodoluminescência representam as áreas analisadas. 
elevados (Figuras 8A e 8B). O diagrama classificatório de Middlemost (1985) mostra uma heterogeneidade composicional das rochas, variando para o Gabronorito Ribeirão do Paiol dentro dos campos de gabro e monzogabro e para o Charnockito São Francisco Xavier dentro dos campos de monzonito e quartzo monzonito (Figura $8 \mathrm{C}$ ). Já o diagrama de índice de aluminosidade (Shand, 1943) mostra que o Gabronorito Ribeirão do Paiol tem caráter fortemente metaluminoso, enquanto as amostras do Charnockito São Francisco Xavier são metaluminosas, posicionadas próximo ao limite com o campo peraluminoso (Figura 8D).

\section{DISCUSSÃO E CONCLUSÃO}

Os dois corpos ígneos estudados (Gabronorito Ribeirão do Paiol e Charnockito São Francisco Xavier) são intrusivos em metagranitoides pertencentes ao BSAL, interpretado como parte de um arco magmático construído entre 670 e 630 Ma, na placa cavalgante Paranapanema, durante sua convergência e posterior colisão com o Cráton do São Francisco no Neoproterozoico (Trouw et al., 2013, Vinagre da Costa et al., 2014a).

Além da natureza química distinta, as idades $\mathrm{U}-\mathrm{Pb}$ em zircão apresentadas neste trabalho descartam uma possível

Tabela 3. Dados isotópicos U-Pb do Charnockito São Francisco Xavier (RDML 60), em que as idades $\mathrm{Pb}_{206} / \mathrm{U}_{238}$ estão dispostas em ordem decrescente.

\begin{tabular}{|c|c|c|c|c|c|c|c|c|c|c|c|c|c|c|c|c|c|}
\hline poro & $\begin{array}{l}{ }^{206} \mathrm{~Pb} \\
(\%)\end{array}$ & $\begin{array}{l}\text { Th } \\
\text { U }\end{array}$ & $\begin{array}{c}{ }^{206} \mathrm{~Pb} \\
{ }^{204} \mathrm{~Pb} \\
(\%)\end{array}$ & $\begin{array}{c}{ }^{207} \mathrm{~Pb} \\
{ }^{206} \mathrm{~Pb} \\
(\%)\end{array}$ & $\begin{array}{c}1 \mathrm{~s} \\
(\%)\end{array}$ & $\begin{array}{c}{ }^{207} \mathrm{~Pb} \\
{ }^{235} \mathrm{U} \\
(\%)\end{array}$ & $\begin{array}{c}\text { 1s } \\
(\%)\end{array}$ & $\begin{array}{c}{ }^{206} \mathrm{~Pb} \\
{ }^{238} \mathrm{U} \\
(\%)\end{array}$ & $\begin{array}{c}1 \mathrm{~s} \\
(\%)\end{array}$ & $\begin{array}{l}{ }^{207} \mathrm{~Pb} \\
{ }^{206} \mathrm{~Pb}\end{array}$ & $1 \mathrm{~s}$ & $\begin{array}{c}{ }^{207} \mathrm{~Pb} \\
{ }^{235} \mathrm{U}\end{array}$ & $1 \mathrm{~s}$ & $\begin{array}{c}{ }^{206} \mathrm{~Pb} \\
{ }^{238} \mathrm{U}\end{array}$ & $1 \mathrm{~s}$ & $\mathrm{P}$ & $\begin{array}{c}\text { Conc } \\
(\%)\end{array}$ \\
\hline 2 & 6 & 5 & 23728 & 0,05992 & 0,7 & 0,83386 & 4 & 0,10093 & 2 &, 7 & 15,9 & 615,8 & 6,6 & 9 & 7,3 & 5 & \\
\hline $12 \mathrm{~b}$ & 07 & 0 & 995 & 06035 & 0,5 & 0,82509 & 1,3 & 0,09916 & 1,2 &, 1 & 10,9 & 610,9 & 6,1 & 609,5 & 7,1 & 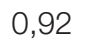 & 99 \\
\hline & 07 & 52 & 25510 & 0,06062 & 1,3 & 0,81940 & 1,6 & 0,09804 & 0,9 & 625,8 & 27,8 & 607,7 & 7,3 & 602,9 & 5,4 & 0,80 & 96 \\
\hline & 4 & 58 & 6001 & 0,05 & 0,6 & 0,80442 & 1,1 & 0,09777 & 0,9 & 591,7 & 13,2 & 599,3 & 4,9 & 601,3 & 5,1 & 0,80 & 01 \\
\hline lob & 02 & 35 & 85467 & 0,05930 & 0,6 & 0,78516 & 1,1 & 0,09604 & 0,9 & 577,9 & 13,4 & 588,4 & 4,9 & 591,1 & 5,2 & 0,93 & 02 \\
\hline & 6 & 44 & 27981 & 0,0 & 0,9 & 0 & 4 & 2 & 1 & 0 & 18,8 & 591,2 & 6,3 & 591,0 & 6,3 & 18 & \\
\hline $9 \mathrm{~b}$ & 0,02 & 0,38 & 77896 & 0,05943 & 0,5 & 0,78622 & 1,0 & 0,09595 & 0,9 & 582,9 & 10,2 & 589,0 & 4,5 & 590,6 & 5,1 & 0,87 & 101 \\
\hline & 04 & ,45 & 40983 & 8 & 0,5 & & 0,8 & & 0,6 & 0 & 10,7 & 588,6 & 3,5 & 0,6 & 3,4 & 73 & \\
\hline 8 & 16 & 0,65 & 11277 & 0,05927 & 1,8 & 0,78054 & 2,1 & 552 & 1,2 & 576,9 & 38,7 & 585,8 & 9,5 & 588,1 & 6,6 & 0,78 & 101 \\
\hline 0 & 2 & 6 & 92871 & 4 & 0,4 & & 0,9 & & 0,8 &, 7 & 8,1 & 583,6 & 4,0 & 7,4 & 4,6 & 90 & \\
\hline & 03 & 0,47 & 50968 & 0,0 & 0,4 & 0,7 & 0,9 & 0, & 0,8 & 575,6 & 9,2 & 584,1 & 4,1 & 586,3 & 4,5 & 0,87 & 10 \\
\hline 32 & 2 & 49 & 8 & 8 & 0,8 & & 1 & & 0,7 & 1,0 & 18,0 & 3,9 & 5,0 & 1,6 & 4 & 84 & \\
\hline & 3 & 0,57 & 59347 & & 0,4 & 0 , & 0,9 & & 0,8 & 4 & 9,6 & 584,3 & 4,2 & & 4,6 & 0,87 & \\
\hline & & & 38 & & c & & 1 & & 1 & 2 & 1 & 9,4 & 5,7 & & 5 & 90 & \\
\hline & 05 & 0,55 & 36682 & 0 & 7 & & 1,1 & & 0 & 6 & 14,6 & 587,9 & 4,7 &, 0 & 4,5 & 0,74 & 6 \\
\hline 23 & 04 & & 4 & & 1 & & 3 & & 7 & & 2 & 2,1 & 9 & 1 & 3,8 & 0,71 & \\
\hline 9 & 0,06 & 0,5 & 27238 & 2 & 0,7 & & 1,4 & & 1,2 & 600,7 & 14,9 & 58 & 6,0 &, 7 & 6,5 & 0,85 & 6 \\
\hline $3 k$ & 0,02 & 0,33 & 113398 & 6 & 0,3 & & 1,0 & & 1,0 & 565,5 & 6,5 & 576,2 & 4,5 &, 9 & 5,5 & 0,95 & \\
\hline $2 b$ & 0,04 & 0,32 & 38556 & 9 & 0,4 & & 1,0 & & 0,9 & 592,3 & 9,2 & 578,9 & 4,3 & 57 & 4,9 & 0,89 & 7 \\
\hline 36 & 0,02 & 0,50 & 84449 & 376 & 0,9 & & 1,4 & 23 & 1,1 & 558,2 & 19,3 & 571,3 & 6,1 & 574,6 & 6,0 & 0,91 & 02 \\
\hline $\mathrm{b}$ & 0,06 & 0,41 & 30164 & 0,0 & 0,8 & 0,7 & 1,3 & 71 & 1,0 & 557,4 & 17,7 & 568,7 & 5,8 & 571,5 & 5,7 & 0,78 & 02 \\
\hline & 02 & 0,61 & 74644 & 0,05909 & 0,4 & 0,7 & 1,2 & 0,09263 & 1,2 & 570,6 & 9,3 & 571,0 & 5,5 & 571,1 & 6,4 & 0,94 & 100 \\
\hline $17 b$ & 0,05 & 0,48 & 34685 & 0,05889 & 0,6 & 0,75169 & 1,0 & 258 & 0,8 & 563,0 & 13,6 & 569,2 & 4,5 & 570,8 & 4,5 & 0,77 & 101 \\
\hline 20 & 08 & 0,41 & 50 & 0,05955 & 0,6 & 387 & 1,2 & 42 & 1,0 & 587,2 & 13,1 & 573,4 & 5,1 & 569,9 & 5,4 & 0,84 & 7 \\
\hline $90 b$ & 0,03 & 0,49 & 60519 & 0,05845 & 0,5 & 0,7 & 0,9 & 0, & 0,8 & 546,6 & 10,0 & 3,3 & 3,8 & 561,2 & 4,1 & 0,84 & 02 \\
\hline & 1 & 0,49 & 86 & 0, & 0,9 & 0,7 & 1,3 & 0 , & 1,0 & 538,7 & 19,1 & 551,3 & 5,6 & 554,3 & 5,3 & 0,74 & 10 \\
\hline 16 & 0,02 & 0,36 & 116 & 0,05880 & 0,5 & 0,72766 & 0,9 & 0,08976 & 0,8 & 559,7 & 11,2 & 555,2 & 4,0 & 554,1 & 4,2 & 0,93 & 9 \\
\hline & 12 & 0,47 & 15382 & 5 & 0,5 & 0,72291 & 1,2 & 378 & 1,0 & 569,1 & 10,8 & 552,4 & 4,9 & 548,3 & 5,5 & 0,89 & 96 \\
\hline $25 b$ & 0,14 & 0,42 & 12538 & 0,05883 & 0,7 & 0,71746 & 1,3 & 8845 & 1,1 & 560,8 & 15,2 & 549,2 & 5,4 & 546,4 & 5,6 & 0,82 & 97 \\
\hline $792 b$ & 0,04 & 0,46 & 37996 & 0,05853 & 0,6 & 0,69720 & 1,4 & 0,08639 & 1,2 & 549,7 & 12,8 & 537,1 & 5,6 & 534,2 & 6,2 & 0,90 & 97 \\
\hline
\end{tabular}


Tabela 4. Dados isotópicos U-Pb do Charnockito São Francisco Xavier (MLR 138), sendo que as idades $\mathrm{Pb}_{206} / \mathrm{U}_{238}$ estão dispostas em ordem decrescente.

\begin{tabular}{|c|c|c|c|c|c|c|c|c|c|c|c|c|c|c|c|c|c|}
\hline $\begin{array}{l}\text { Análises } \\
\text { b-borda }\end{array}$ & $\begin{array}{c}{ }^{206} \mathrm{~Pb} \\
(\%)\end{array}$ & $\begin{array}{l}\text { Th } \\
\text { U }\end{array}$ & $\begin{array}{c}{ }^{206} \mathrm{~Pb} \\
{ }^{204} \mathrm{~Pb} \\
(\%)\end{array}$ & $\begin{array}{c}{ }^{207} \mathrm{~Pb} \\
{ }^{206} \mathrm{~Pb} \\
(\%)\end{array}$ & $\begin{array}{l}1 \mathrm{~s} \\
(\%)\end{array}$ & $\begin{array}{c}{ }^{207} \mathrm{~Pb} \\
{ }^{235} \mathrm{U} \\
(\%)\end{array}$ & $\begin{array}{l}1 \mathrm{~s} \\
(\%)\end{array}$ & $\begin{array}{c}{ }^{206} \mathrm{~Pb} \\
{ }^{238} \mathrm{U} \\
(\%)\end{array}$ & $\begin{array}{l}1 \mathrm{~s} \\
(\%)\end{array}$ & $\begin{array}{l}{ }^{207} \mathrm{~Pb} \\
{ }^{206} \mathrm{~Pb}\end{array}$ & $1 \mathrm{~s}$ & $\begin{array}{l}{ }^{207} \mathrm{~Pb} \\
{ }^{235} \mathrm{U}\end{array}$ & 1s & $\begin{array}{c}{ }^{206} \mathrm{~Pb} \\
{ }^{238} \mathrm{U}\end{array}$ & $1 \mathrm{~s}$ & Rho & $\begin{array}{c}\text { Conc } \\
(\%)\end{array}$ \\
\hline
\end{tabular}

\begin{tabular}{llllllllllllllllllllllll}
\hline $070-Z 371$ & 0,0200 & 0,6258 & 88271,52 & 0,0602 & 1,0194 & 0,8571 & 1,2787 & 0,1033 & 0,7720 & 609,4 & 22,0 & 628,5 & 6,0 & 633,9 & 4,7 & 0,7979 & 104
\end{tabular}

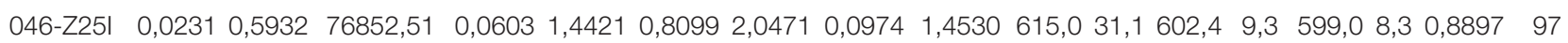

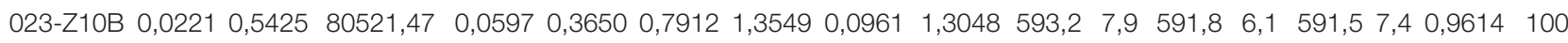

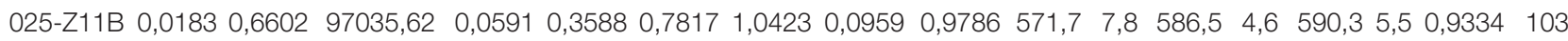
077-Z44N 0,0363 0,9902 39325,90 0,0588 0,4659 0,7732 1,0519 0,0954 0,9431 558,6 10,2 581,6 $4,7 \quad 587,5$ 5,3 $0,8866 \quad 105$ 060-Z31N 0,0392 0,8090 45355,21 $0,0592 \quad 0,86050,7746 \begin{array}{llllllllllllllll}1,1792 & 0,0949 & 0,8063 & 573,4 & 18,7 & 582,4 & 5,2 & 584,7 & 4,5 & 0,8521 & 102\end{array}$ $\begin{array}{llllllllllllllllllllllll}0.98-Z 16 B & 0,0264 & 0,6033 & 71544,69 & 0,0597 & 0,4225 & 0,7814 & 1,1775 & 0,0949 & 1,0991 & 592,8 & 9,2 & 586,3 & 5,2 & 584,6 & 6,1 & 0,9288 & 98\end{array}$

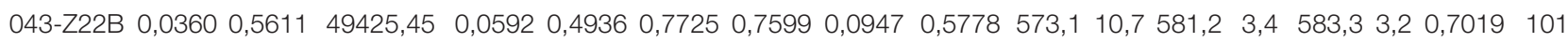
065-Z34N 0,0781 0,8135 22764,74 0,0595 1,0969 $0,7693 \begin{array}{lllllllllllllllllll}1,3277 & 0,0937 & 0,7481 & 586,3 & 23,8 & 579,3 & 5,9 & 577,6 & 4,1 & 0,5264 & 98\end{array}$ $\begin{array}{lllllllllllllllllllllll}057-Z 29 N & 0,0186 & 0,6163 & 95546,27 & 0,0590 & 0,3556 & 0,7575 & 0,7520 & 0,0932 & 0,6626 & 565,3 & 7,7 & 572,6 & 3,3 & 574,4 & 3,6 & 0,8554 & 101\end{array}$ $\begin{array}{lllllllllllllllllllllllll}019-Z 9 N & 0,0828 & 0,7175 & 21479,96 & 0,0597 & 1,2894 & 0,7669 & 1,5682 & 0,0932 & 0,8925 & 592,6 & 28,0 & 578,0 & 6,9 & 574,3 & 4,9 & 0,5438 & 96\end{array}$

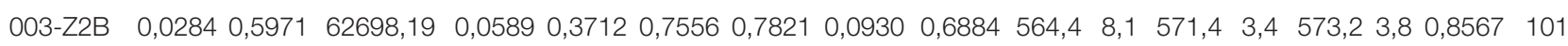
$\begin{array}{llllllllllllllllllllllll}0,76-Z 29 B & 0,0215 & 0,4902 & 82889,73 & 0,0588 & 0,8396 & 0,7531 & 1,0590 & 0,0929 & 0,6453 & 559,6 & 18,3 & 570,0 & 4,6 & 572,7 & 3,5 & 0,7928 & 102\end{array}$ $\begin{array}{llllllllllllllllllllllll}0, Z 28 N & 0,0369 & 0,6693 & 53763,59 & 0,0596 & 0,4639 & 0,7633 & 0,8091 & 0,0928 & 0,6629 & 590,3 & 10,1 & 575,9 & 3,6 & 572,2 & 3,6 & 0,7840 & 96\end{array}$

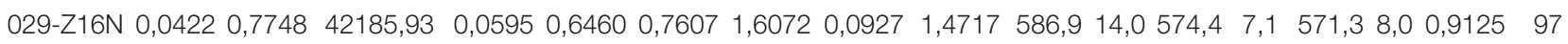

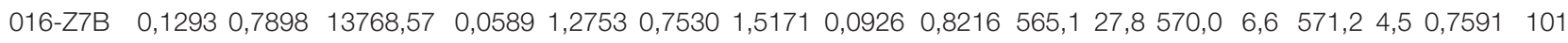

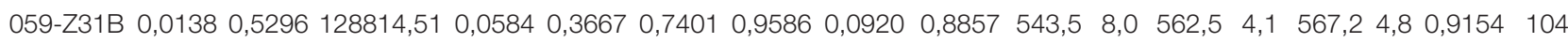

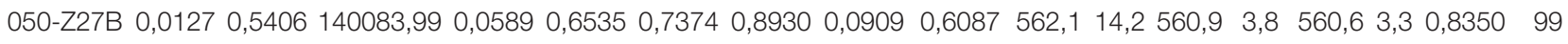

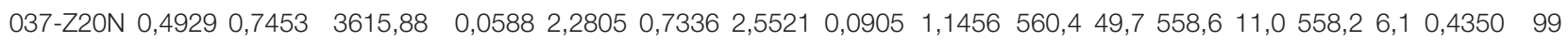
$\begin{array}{lllllllllllllllllll}017-Z 8 N & 0,0900 & 0,9509 & 19824,19 & 0,0576 & 0,9545 & 0,6985 & 1,3926 & 0,0879 & 1,0141 & 515,1 & 21,0 & 537,9 & 5,8 & 543,3 & 5,3 & 0,7110 & 105\end{array}$ $\begin{array}{lllllllllllllllllllllll}0,14-Z 6 B & 1,2790 & 0,5412 & 1264,96 & 0,0588 & 1,5036 & 0,7057 & 1,6536 & 0,0870 & 0,6881 & 560,9 & 32,8 & 542,2 & 6,9 & 537,8 & 3,6 & 0,3770 & 95\end{array}$

Tabela 5. Análises Sm-Nd para amostras do Charnockito São Francisco Xavier (RDML 60) e do Gabronorito Ribeirão do Paiol (MLR 292).

\begin{tabular}{ccccccccccc}
\hline & $\begin{array}{c}(143 \mathrm{Nd} / \\
\left.{ }^{144} \mathrm{Nd}\right)_{\mathrm{i}}\end{array}$ & $\begin{array}{c}{ }^{1443} \mathrm{Nd} / \\
{ }^{140 M}\end{array}$ & $\begin{array}{c}{ }^{(143} \mathrm{Nd} / \\
\left.{ }^{144} \mathrm{Nd}\right)_{0}\end{array}$ & $\begin{array}{c}{ }^{147} \mathrm{Sm} / \\
{ }^{144} \mathrm{Nd}\end{array}$ & $\mathrm{TDM}_{\mathrm{i}}(\mathrm{Ga})$ & $\mathrm{T}(\mathrm{Ga})$ & $\mathrm{ENd}(0)$ & $\mathrm{ENd}(\mathrm{T})$ & $\mathrm{I}(\mathrm{T})$ & $\mathrm{E}(\mathrm{TDM})$ \\
\hline RDML 60 & 0,511255 & 0,510206 & 0,511675 & 0,110481 & 2,02 & 0,58 & $-18,79$ & $-12,41$ & 0,51 & 3,46 \\
MLR 292 & 0,511580 & 0,511023 & 0,511903 & 0,093002 & 1,44 & 0,53 & $-14,34$ & $-7,32$ & 0,51 & 4,70 \\
\hline
\end{tabular}

Tabela 6. Elementos maiores (\%peso) e traço (ppm) de amostras do Gabronorito Ribeirão do Paiol e do Charnockito São Francisco Xavier.

\begin{tabular}{|c|c|c|c|c|c|c|c|c|c|c|c|c|c|c|c|c|c|c|c|c|c|c|c|c|c|}
\hline & & $\mathrm{O}_{2}$ & $\mathrm{O}_{2}$ & ${ }_{2} \mathrm{O}_{3}$ & $\mathrm{e}_{2} \mathrm{O}_{3}$ & & & & $\mathrm{Na}_{2} \mathrm{O}$ & $\mathrm{K}_{2} \mathrm{O}$ & $\mathrm{P}_{2} \mathrm{O}_{5}$ & & & V & $r$ & & $\mathrm{Ni}$ & $n$ & ( & & & $Y$ & $r$ & b & to \\
\hline & & & & & & & & & & & & & & & & & & & & & & & & & \\
\hline & & & & & & & & & & & & & & & & & & & & & & & & 9 & \\
\hline & & & & & & & & & & & & & & & & 24 & & & & & & & & & \\
\hline & & & & & & & & & & & & & & & & & & & & & & & & 17 & \\
\hline & & & & & & & & & & & & & & & 56 & 3 & 33 & & & & & & & 16 & \\
\hline & & & $B$ & & & & & & & & & & & 127 & 2 & 32 & 31 & 92 & 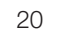 & 92 & 298 & & 519 & 6 & 17 \\
\hline & & & & & 02 & & & & & & & & & & & & & & & 27 & & & & & \\
\hline DPA 74 B & ito & 45,90 & 10 & 16,24 & 13,06 & 0,13 & 6,70 & 9,02 & 3,07 & 2,12 & 72 & 0,67 & 99,73 & 197 & 135 & 50 & 35 & 104 & 18 & 44 & 673 & 18 & 1 & -2 & 700 \\
\hline
\end{tabular}


relação genética entre as rochas estudadas, uma vez que diferem em aproximadamente $45 \mathrm{Ma}$. Cristais de zircão do Charnockito São Francisco Xavier forneceram idade de cristalização de 579 Ma, enquanto o Gabronorito Ribeirão do Paiol apresentou idade de cristalização de $534 \mathrm{Ma}$.

Os escassos dados $\mathrm{Sm}-\mathrm{Nd}$ disponíveis apontam contaminação ou participação de componentes crustais na evolução do magma que originou tanto o Gabronorito Ribeirão do Paiol quanto o Charnockito São Francisco Xavier, sendo que este último apresenta valor negativo mais elevado de $\varepsilon_{\mathrm{Nd}}(\mathrm{t})$.
Trabalhos anteriores (Janasi, 1999; Campos Neto e Caby, 1999, 2000; Trouw et al., 2000, 2013; Hackspacher et al., 2003; Heilbron et al., 2004; Campos Neto et al., 2004, 2011; Peternel et al., 2005; Trouw, 2008; Vinagre da Costa et al., 2014a) mostram que essa região é caracterizada por um metamorfismo colisional com idade variando de 630 a $610 \mathrm{Ma}$, relacionado ao cavalgamento entre os paleoblocos Paranapanema e São Francisco. Tal evento metamórfico foi sobreposto por outro metamorfismo regional com idade entre 590 e $570 \mathrm{Ma}$, relacionado ao cavalgamento da microplaca Serra do Mar
A

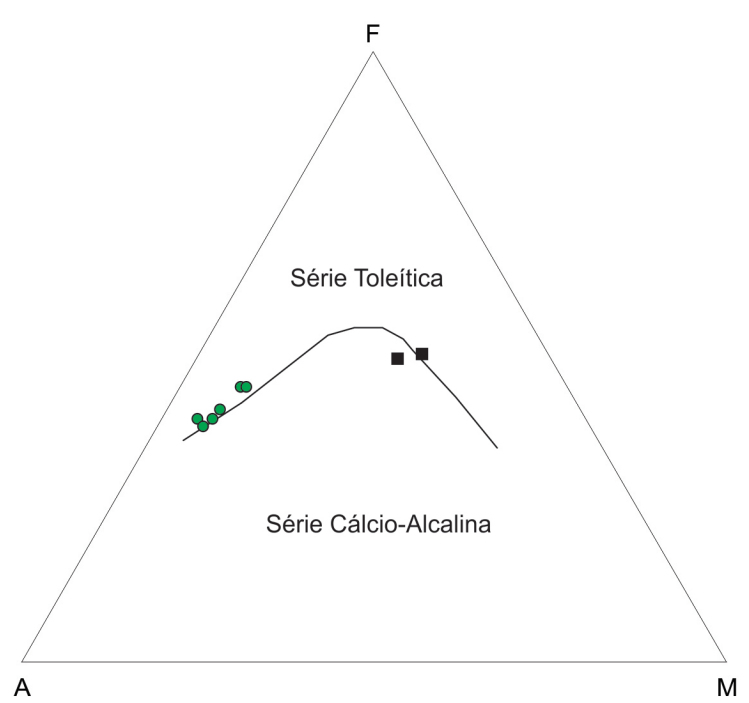

C

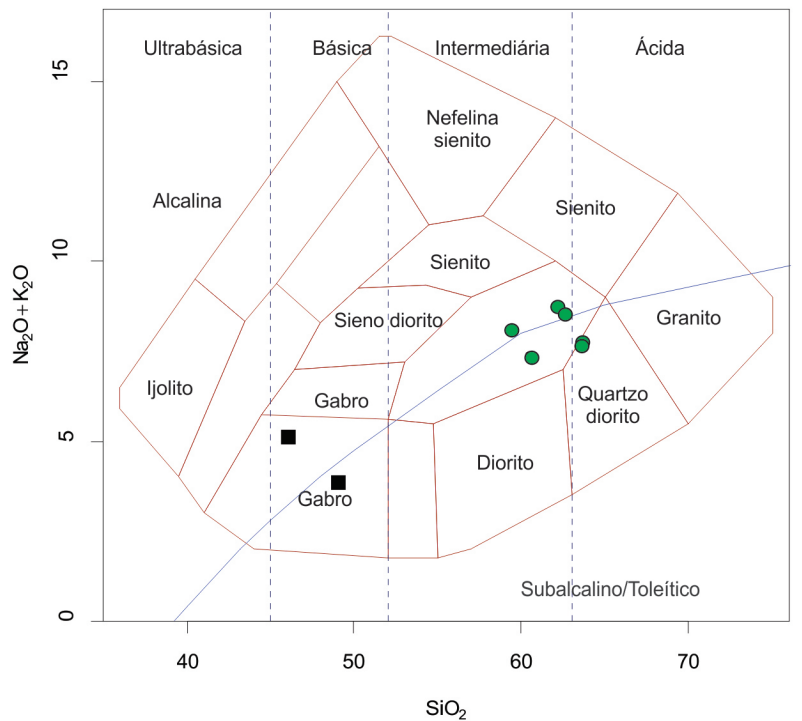

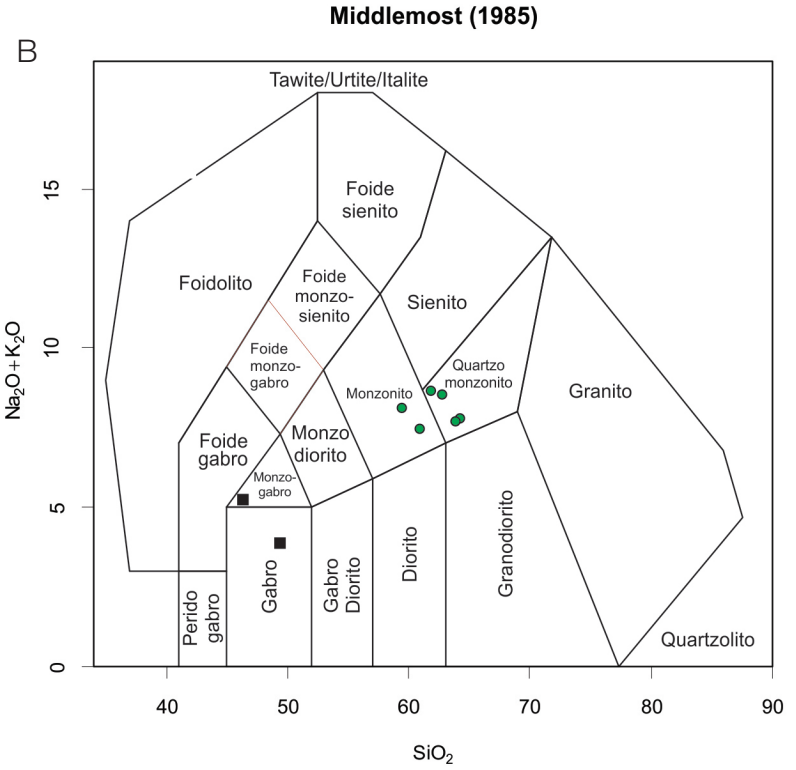

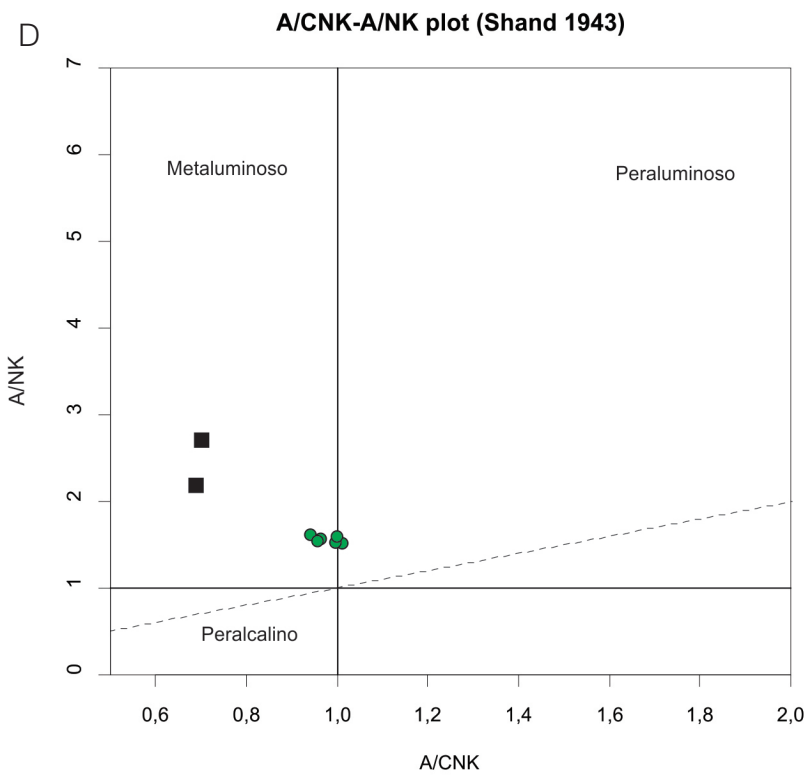

Figura 8. Diagramas discriminantes para as amostras do Gabronorito Ribeirão do Paiol (quadrado preto) e do Charnockito São Francisco Xavier (círculo verde). (A) AFM (Irvine e Baragar, 1971); (B) $\mathrm{Na}_{2} \mathrm{O}+\mathrm{K}_{2} \mathrm{O} \times \mathrm{SiO}_{2}(\mathrm{Cox}$ et al., 1979); (C) Na $\mathrm{O}$ $+\mathrm{K}_{2} \mathrm{O} \times \mathrm{SiO}_{2}$ (Middlemost, 1985); (D) A/NK $\times$ A/CNK (Shand, 1943). 
(onde estava instalado o arco magmático Rio Negro) sobre o bloco Paranapanema/São Francisco, no desenvolvimento do Orógeno Ribeira Central (Heilbron et al., 2004, 2008).

De acordo com os dados apresentados neste trabalho, corroborando as conclusões de Negri (2002), o Charnockito São Francisco Xavier estaria associado ao retrabalhamento e à fusão crustal relacionada à elevação de temperatura durante o evento colisional da Faixa Ribeira. No entanto, outra possibilidade aqui aventada seria a relação do charnockito com processos extensionais tardios localizados no extremo sul do Cinturão Brasília Meridional. A geologia da bacia sedimentar Pico do Itapeva (Figura 2), localizada nas proximidades de Campos do Jordão, também pode ser aqui abordada quanto à extensão crustal da região estudada. Essa bacia tem sua sedimentação balizada entre 610 e $540 \mathrm{Ma}$ (Juliani et al., 1990; Teixeira, 2000; Campos Neto et al., 2004; Caputo Neto, 2016) e sofreu metamorfismo até fácies xisto verde, zona de biotita, com clivagem mergulhando predominantemente para SE. A idade máxima de sedimentação mostra que as rochas da bacia foram depositadas, metamorfizadas e deformadas após o ápice evolutivo da Faixa Brasília Meridional (630 - 610 Ma), implicando que o metamorfismo e as estruturas presentes nas rochas estariam associados à evolução da Faixa Ribeira Central. Assumindo essa hipótese, a idade de cristalização do charnockito ocorre dentro do intervalo de sedimentação da bacia, sendo possível que a origem desse magmatismo esteja associada ao processo de extensão que gerou a bacia.

Outro fator que deve ser levado em consideração é que as rochas metassedimentares da Bacia Pico do Itapeva estão colocadas em discordância sobre metagranitoides do BSAL, que teve sua cristalização determinada entre 670 e $630 \mathrm{Ma}$, a uma profundidade de aproximadamente $17 \mathrm{~km}$ (Vinagre da Costa et al., 2014b). Como o BSAL foi metamorfizado durante a colisão relacionada à Faixa Brasília Meridional, entre $630 \mathrm{e}$ $610 \mathrm{Ma}$, é importante ressaltar o soerguimento dessas rochas de arco, já que elas estavam expostas na superfície terrestre a ponto de corresponderem à base onde foram depositados os sedimentos que originaram a Bacia Pico do Itapeva.

O Gabronorito Ribeirão do Paiol, possível representante de magmatismo mantélico, cristalizou aproximadamente em $534 \mathrm{Ma}$, posteriormente ao pico metamórfico da Faixa Ribeira Central. Uma possível interpretação para a colocação desse corpo seria admitir que nessa época, por volta de $534 \mathrm{Ma}$, o orógeno da Faixa Ribeira Central já se encontrava em colapso, com extensão crustal, o que poderia trazer o manto astenosférico dessa porção terrestre mais próximo da superfície, injetando corpos magmáticos, mas também aquecendo a crosta o suficiente para produzir um significativo volume de magma por fusão crustal. Nesse caso, é provável que alguns dos corpos ígneos de igual idade ou um pouco mais velhos que o gabronorito, atualmente tidos como produtos da fusão crustal relacionada ao metamorfismo colisional da Faixa Ribeira Central, poderiam ser na verdade produtos de eventos extensionais relacionados ao colapso do orógeno. Investigações isotópicas e geofísicas futuras são essenciais para testar tal hipótese. Na região estudada são encontrados diversos diques máficos de variadas espessuras e com idades não definidas na literatura, que podem ser representantes de volumoso magmatismo básico não aflorante. Não seria impossível que tais rochas, em parte, tivessem idades de cristalização do fim do Pré-cambriano, estando associadas ao gabronorito.

Processos similares são reportados por outros autores em regiões distintas, como, por exemplo, no Cinturão Granitoide Rapakivi Itu (Vlach et al., 1990) ou na Província Rapakivi Itu (Wernick et al., 1993, 1997), mais tarde definida por Janasi et al. (2009) como Província Granítica de Itu. Tal província foi interpretada como produto de um magmatismo pós-orogênico com componente extensional associado à Faixa Brasília Meridional, com idade entre 590 e $580 \mathrm{Ma}$ (Janasi et al., 2009). Bolonini et al. (2013) reportaram que o Maciço Granítico Capão Bonito (SP) é produto de um magmatismo pós-orogênico a anorogênico de ambiente intraplaca, com fusão de material da crosta inferior associado a um ambiente extensional ao final do evento colisional da Orogênese Apiaí. Além desses, De Campos et al. (2016) mostram que ocorrem na Faixa de Dobramentos Araçuaí granitos (e rochas máficas) pós-orogênicos, produtos de extensão crustal, a mesma interpretação dada por Valeriano et al. (2016) para corpos graníticos pós-orogênicos inseridos na Faixa Ribeira Central.

\section{AGRADECIMENTOS}

Agradecemos o apoio financeiro do Serviço Geológico do Brasil por meio do Programa de Geologia do Brasil (PRONAGEO), assim como ao Conselho Nacional de Desenvolvimento Científico e Tecnológico (CNPq), à Fundação de Amparo à Pesquisa do Estado do Rio de Janeiro (FAPERJ) e aos revisores (anônimos) por todas as sugestões que melhoraram a qualidade do trabalho.

\section{REFERÊNCIAS}

Basei, M. A. S., Siga Jr., O., Sato, K., Sproesser, W. M. (1995). A metodologia Urânio-Chumbo na USP. Princípios metodológicos, aplicações e resultados obtidos. Anais Academia Brasileira de Ciências, 67, 221-238.

Bento dos Santos, T., Munhá, J., Tassinari, C., Fonseca, P. (2011). The link between partial melting, granitization and granulite development in central Ribeira Fold Belt, SE Brazil: new evidence from elemental and $\mathrm{Sr}-\mathrm{Nd}$ isotopic geochemistry. Journal of South American Earth Sciences, 31(2-3), 262-278. DOI: 10.1016/j.jsames.2011.01 
Best, M. G. (1982). Igneous and metamorphic petrology. Nova York: W. H. Freeman and Company.

Bolonini, T. M., Godoy, A. M., Saar, L. C. A. (2013). Geologia e Litogeoquímica das Rochas Graníticas do Maciço Capão Bonito e O Contexto Geológico da Sequência Vulcanosedimentar Açungui. Geociências, 32(3), 452-470.

Bühn, B., Pimentel, M. M., Matteini, M., Dantas, E. L. (2009). High Spatial Resolution Analysis of $\mathrm{Pb}$ and U Isotopes For Geochronology by Laser Ablation Multi-Collector Inductively Coupled Plasma Mass Spectrometry (La-Mc-Icp-Ms). Anais da Academia Brasileira de Ciências, 81, 99-114. http:// dx.doi.org/10.1590/S0001-37652009000100011

Campos Neto, M. C. (2000). Orogenic systems from southwestern Gondwana, an approach to Brasiliano-pan African Cycle and orogenic collage in southeastern Brazil. In: U. G. Cordani, E. J. Milani, A. Thomaz Filho, D. A. Campos (Eds.), Tectonic Evolution of South America (335-365). 31 $1^{\text {st }}$ International Geological Congress, Rio de Janeiro, Brazil.

Campos Neto, M. C., Basei, M. A. S., Janasi, V. A., Moraes, R. (2011). Orogen Migration and Tectonic Setting of the Andrelândia Nappe System: an Ediacaran Western Gondwana Collage, South of São Francisco Craton. Journal of South American Earth Sciences, 32, 393-406. https://doi. org/10.1016/j.jsames.2011.02.006

Campos Neto, M. C., Basei, M. A. S., Vlach, S. R. F., Caby, R., Szabó, G. A. J., Vasconcelos, P. (2004). Migração de orógenos e superposição de orogêneses: um esboço da colagem Brasiliana no sul do Cráton do São Francisco, SE-Brasil. Geologia USP. Série Cientifica, 4(1), 13-40. http://dx.doi. org/10.5327/S1519-874x2004000100002

Campos Neto, M. C., Caby, R. (1999). Neoproterozoic highpressure metamorphism and tectonic constraint from the nappe system south of the São Francisco Craton, southeast Brazil. Precambrian Research, 97, 3-26.

Campos Neto, M. C., Caby, R. (2000). Terrane accretion and upward extrusion of high-pressure granulites in the Neoproterozoic nappes of southeast Brazil: Petrologic and structural constraints. Tectonics, 19, 669-687. DOI: 10.1029/1999TC900065

Campos Neto, M. C., Cioffi, C. R., Moraes, R., Motta, R. G., Siga Jr., O., Basei, M. A. S. (2010). Structural and metamorphic control on the exhumation of high-P granulites: the Carvalhos Klippe example, from the oriental Andrelândia Nappe System, southern portion of the Brasília Orogen,
Brazil. Precambrian Research, 180, 125-142. DOI: 10.1016/j. precamres.2010.05.010

Caputo Neto, V. (2016). A Formação Pico do Itapeva, Região de Campos do Jordão, São Paulo: Mapeamento Geológico, Associações de Fácies e Geocronologia U-Pb. Dissertação (Mestrado). Rio de Janeiro: Instituto de Geociências - UFRJ.

Cavalcante, J., Cunha, H. C. S., Chieregatti, L. A., Kaefer, L. Q., Rocha, J. M., Daitx, E. C., Coutinho, M. G. N., Yamamoto, K., Drumond, J., Rosa, D. B., Ramalho, R. (1979). Projeto Sapucaí, estado de São Paulo, Rio de Janeiro e Minas Gerais, Relatório Final de Geologia. Brasília: DNPM/CPRM.

Condie, K. C. (1989). Plate tectonics and crustal evolution. $3^{\mathrm{a}}$ ed. Novo México: Pergamon Press.

Cox, K. G., Bell, J. D., Pankhurst, R. J. (1979). The interpretation of igneous rocks. Londres: George Allen \& Unwin.

De Campos, C. P., Medeiros, S. R., Mendes, J. C., PedrosaSoares, A. C., Dussin, I., Ludka, I. P., Dantas, E. L. (2016). Cambro-Ordovician Magmatism in the Araçuaí orogen (SE Brazil): snapshots from a late orogenic collapse. Journal of South American Earth Sciences, 68. DOI: 10.1016/j. jsames.2015.11.016

Duffles, P., Trouw, R. A. J., Mendes, J. C., Gerds, A., Vinagre, R. (2016). U-Pb age of detrital zircon from the Embu Sequence, Ribeira Belt, Se Brazil. Precambrian Research, 278, 69-86. https://doi.org/10.1016/j.precamres.2016.03.007

Hackspacher, P. C., Fetter, A. H., Ebert, H. D., Janasi, V. A., Dantas, E. L., Oliveira, M. A. F., Braga, I. F., Negri, F. A. (2003). Magmatismo há 660-640 Ma no Domínio Socorro: registros de convergência pré-colisional na aglutinação do Gondwana Ocidental. Geologia USP. Série Cientifica, 3, 85-96. http://dx.doi.org/10.5327/S1519-874X2003000100007

Heilbron, M., Duarte, B., Valladares, C., Nogueira, J. R., Tupinambá, M., Eirado, L. G. (2003). Síntese Geológica do Bloco Oriental (Zona da Mata). In: A. C. Pedrosa Soares, C. M. Noce, R. Trouw, M. Heilbron (Eds.), Projeto Sul de Minas, Belo Horizonte (8-50). Minas Gerais: COMIG/SEME. 1(2).

Heilbron, M., Pedrosa-Soares, A. C., Campos Neto, M., Silva, L. C., Trouw, R. A. J., Janasi, V. C. (2004). A Província Mantiqueira. In: V. Mantesso-Neto, A. Bartorelli, C. D. R. Carneiro, B. B. Brito Neves (Eds.), O desvendar de um continente: a moderna geologia da América do Sul e o legado da obra de Fernando Flávio Marques de Almeida, 203-234. São Paulo: Beca. 
Heilbron, M., Valeriano, C. M., Tassinari, C. C. G., Almeida, J. C. H., Tupinambá, M., Siga Jr., O., Trouw, R. A. J. (2008). Correlation of Neoproterozoic terranes between the Ribeira Belt, SE Brazil and its African counterpart: comparative tectonic evolution and open questions. In: R. J. Pankhurst, R. A. J. Trouw, B. B. Brito-Neves, M. de Wit (Eds.), West Gondwana pre-Cenozoic Correlations across the South Atlantic Region. Journal Geological Society London, Special Publication, 294, 211-232.

Irvine, I. N., Baragar, W. R. A. (1971). A Guide to the Chemical Classification of the Common Volcanic Rocks. Canadian Journal of Earth Sciences, 8(5), 523-548. http:// dx.doi.org/10.1139/e71-055

Janasi, V. A. (1999). Petrogênese de granitos crustais na Nappe de Empurrão Socorro Guaxupé (SP-MG): uma contribuição da geoquímica elemental e isotópica. Tese (Doutorado). São Paulo: Instituto de Geociências - USP.

Janasi, V.A. (2002). Elemental and Sr-Nd isotope geochemistry of two Neoproterozoic mangerite suites in SE Brazil: implications for the origin of the magerite-charnockitegranite series. Precambrian Research, 119, 301-327.

Janasi, V. A., Alves, A., Vlach, S. R. F., Leite, R. J. (2003). Granitos peraluminosos da porção central da Faixa Ribeira, Estado de São Paulo: Sucessivos eventos de reciclagem da crosta continental no Neoproterozóico. Geologia USP. Série Científica, 3, 13-24. http://dx.doi.org/10.5327/ S1519-874X2003000100002

Janasi, V. A., Vlach, S. R. F., Campos Neto, M. C., Ulbrich, H. H. G. J. (2009). Associated A-Type subalkaline and high-K calcalkaline granites in the Itu Granite Province, Southeastern Brazil: Petrological and tectonic significance. Canadian Mineralogist, 47, 1505-1526. https://doi.org/10.3749/canmin.47.6.1505

Juliani, C., Riccomini, C., Barros, E. J., Batistucci, N. L. N. (1990). Proterozoic storm-dominated sedimentation in the Pico de Itapeva Formation (São Paulo State, Brazil). In: Reunião Anual da Academia Brasileiras de Ciências, São Paulo. Anais da Academia Brasileiras de Ciências, 62, 105-105.

Middlemost, E. A. K. (1985). Magmas and magmatic rocks: an introduction to igneous petrology. Harlow: Longman Group Limited, Essex.

Miller, C. F., McDowell, S. M., Mapes, E. W. (2003). Hot and cold granites? Implications for zircon saturation temperatures and preservation of inheritance. Geology, 31(6), 529-532. https://doi.org/10.1130/0091-7613(2003)031\%3C0529:H ACGIO\%3E2.0.CO;2
Negri, F.A. (2002). Petrologia das rochas charnockitograníticas e encaixantes de alto grau associadas na região de São Francisco Xavier, SP. Tese (Doutorado). Rio Claro: Instituto de Geociências e Ciências Exatas - UNESP.

Negri, F. A., Oliveira, M. A. (2005). Geoquímica e Geotermimetria dos Granulitos Máficos Associados às Rochas Supracrustais da Extremidade Meridional do Domínio Socorro, Região de São Francisco Xavier, SP. Revista Brasileira de Geociências, 35(4), 591-602. DOI: 10.25249/0375-7536.200535591602

Oliveira, E. C., Lafon, J. M., Gioia, S. M., Pimentel, M. M. (2008). Datação Sm-Nd em rocha total e granada do metamorfismo granulítico da região de Tartarugal Grande, região Central do Amapá (NE do Bloco Arqueano Amapá). Revista Brasileira de Geociências, 38, 114-127.

Oliveira, M. A. F., Carvalho, S. G., Morales, N., Choudhuri, A., Angeli, N., Godoy, A. M., Rueda, J. R. J. (1983). Geologia das Folhas de Camanducaia e Monteiro Lobato na escala, 1:50.000 (porção paulista). Relatório Final. São Paulo: SCCTC-UNESP, inédito, 83, anexos.

Peternel, R., Trouw, R. A. J., Schmitt, R. (2005). Interferência entre duas faixas móveis neoproterozóicas: o caso das faixas Brasília e Ribeira, no sudeste do Brasil. Revista Brasileira de Geociências, 35, 297-310.

Peternel, R., Trouw, R. A. J., Vinagre, R., Fontainha, M., Correa, R., Reis, R., Meireles, M., Lages, M. (2014). Mapa Geológico da Folha Campos do Jordão 1:100.000, Programa Geologia do Brasil, PRONAGEO, Universidade Federal do Rio de Janeiro, CPRM.

Reno, B. L., Brown, M., Kobayashi, K., Nakamura, E., Piccoli, P. M., Trouw, R. A. J. (2009). Eclogite-highpressure granulite metamorphism records early collision in West Gondwana: new data from the Southern Brasília Belt, Brazil. Journal Geological Society, 166, 1013-1032. https://doi.org/10.1144/0016-76492008-140

Reno, B. L., Brown, M., Piccoli, P. M. (2010). ${ }^{40} \mathrm{Ar} /{ }^{39} \mathrm{Ar}$ thermochronology of high-pressure granulite nappes in the southern Brasília Belt, Brazil: implications for nappe exhumation. American Journal of Science, 310, 1294-1332. DOI: $10.2475 / 10.2010 .04$

Reno, B. L., Piccoli, P. M., Brown, M., Trouw, R. A. J. (2012). In situ monazite (U-Th)-Pb ages from the Southern Brasília Belt, Brazil: constraints on the high-temperature retrograde evolution of HP granulites. Journal of Metamorphic Geology, 30, 81-112. DOI: 10.1111/j.1525-1314.2011.00957.x 
Sadowski, G. R., Carneiro, C. D. R. (1974). O charnockito de São Francisco Xavier, São Paulo. In: XXVIII Congresso Brasileiro de Geologia, Anais 4, 207-211. Porto Alegre: SBG.

Shand, S. J. (1943). The eruptive rocks. $2^{\mathrm{a}}$ ed. Nova York: John Wiley \& Sons.

Teixeira, A. L. (2000). Análise das bacias da transição Proterozóico-Fanerozóico do Estado de São Paulo e adjacências. Tese (Doutorado). São Paulo: Instituto de Geociências - USP.

Trouw, C. C. (2008). Mapeamento da Folha Virgínia-MG, Geocronologia U-Pb (SHRIMP) em zircão e interpretação geotectônica. Tese (Doutorado). Rio de Janeiro: Instituto de Geociências - UFRJ.

Trouw, R. A. J., Heilbron, M., Ribeiro, A., Paciullo, F. V. P., Valeriano, C. M., Almeida, J. C. H., Tupinambá, M., Andreis, R. R. (2000). The central segment of the Ribeira belt. In: U. G. Cordani, E. J. Milani, A. Thomaz Filho, D. A. Campos (Eds.), Tectonic Evolution of South America (287-310). $31^{\text {th }}$ International Geological Congress, Rio de Janeiro, Brasil.

Trouw, R. A. J., Peternel, R., Ribeiro, A., Heilbron, M., Vinagre, R., Duffles, P., Trouw, C. C., Fontainha, M., Kussama, H. (2013). A New Interpretation for the Interference Zone between the Southern Brasília Belt and the Central Ribeira Belt, SE Brazil. Journal of South American Earth Sciences, 48, 43-57. DOI: 10.1016/j.jsames.2013.07.012

Trouw, R. A. J., Peternel, R., Vinagre, R., Trouw, C., Matos, G., Duffles, P., Fontainha, M. (2014). Mapa Geológico da Folha Pindamonhangaba 1:100.000, Programa Geologia do Brasil, PRONAGEO, Universidade Federal do Rio de Janeiro, CPRM.

Tupinambá, M., Teixeira, W., Heilbron, M. (2012). Evolução Tectônica e Magmática da Faixa Ribeira entre o Neoproterozoico e o Paleozoico Inferior na Região Serrana do Estado do Rio de Janeiro, Brasil. Anuário do Instituto de Geociências da UFRJ, 35(2), 140-151. http://dx.doi. org/10.11137/2012_2_140_151

Valeriano, C. M., Machado, N., Simonetti, A., Valladares, C. S., Seer, H. J., Simões, L. S. A. (2004). U-Pb geochronology of the southern Brasilia belt (SE-Brazil): sedimentary provenance, Neoproterozoic orogeny and assembly of West Gondwana. Precambrian Research, 130, 27-55. http://dx.doi. org/10.1016/j.precamres.2003.10.014

Valeriano, C. M., Mendes, J. C., Tupinambá, M., Bongiolo, E., Heilbron, M., Junho, M. C. B. (2016). Cambro-Ordovician post-collisional granites of the Ribeira Belt, SE-Brazil: a case of terminal magmatism of a hot orogen. Journal of South American Earth Sciences, 68, 269-281.DOI: 10.1016/j.jsames.2015.12.014

Valeriano, C. M., Pimentel, M., Heilbron, M., Trouw, R. A. J., Almeida, J. C. (2008). Tectonic evolution of the Brasília Belt, Central Brazil, and early assembly of Gondwana. In: R. J. Pankhurst, R. A. J. Trouw, B. B. Brito Neves, M. J. de Wit (Eds.), West Gondwana: Pre-Cenozoic Correlations across the South Atlantic Region. Geological Society of London, Special Publications, 294, 197-210.

Vinagre, R., Trouw, R. A. J., Mendes, J. C., Duffles, P., Peternel, R., Matos, G. (2014a). New Evidence of a Magmatic Arc in the Southern Brasília Belt, Brazil: The Serra da Água Limpa Batholith (Socorro-Guaxupé Nappe). Journal of South American Earth Science, 54, 120-139. https://doi. org/10.1016/j.jsames.2014.05.002

Vinagre, R., Trouw, R. A. J., Mendes, J. C., Ludka, I. (2014b). Química mineral e geotermobarometria do Batólito Serra da Água Limpa, Nappe Socorro-Guaxupé, Faixa Brasília Meridional, Sudeste do Brasil. Brazilan Journal of Geology, 44(3), 387-414. http://dx.doi.org/10.5327/ Z2317-4889201400030005

Vlach, S. R., Janasi, V. A., Vasconcellos, A. C. B. (1990). The Itu belt: associated calc-alkaline and aluminous A-type late Brasiliano granitoids in the states of São Paulo and Paraná, southern Brazil. In: XXXVI Congresso Brasileiro de Geologia, 4, 1700-1711. Natal: SBG.

Watson, E. B., Harrison, T. M. (1983). Zircon saturation revisited: temperature and composition effects in a variety of crustal magma types. Earth and Planetary Science Letters, 64, 295-304. https://doi.org/10.1016/0012-821X(83)90211-X

Wernick, E., Galembeck, T. M. B., Godoy, A. M., Hörmann, P. K. (1997). Geochemical variability of the Rapakivi Itu Province, State of São Paulo, SE Brazil. Anais da Academia Brasileira de Ciências, 69, 395-413.

Wernick, E., Godoy, A. M., Ferreira, C. J., Galembeck, T. M. B., Artur, A. C., Andrade, F. R. D. (1993). Estruturação e Evolução Magmática de Granitóides Associados a Falha Transcorrente (Estado de São Paulo, SE Brasil): um Estudo Comparativo. In: III Simpósio de Geologia do Sudeste, 1, 87-89. Rio de Janeiro: SBG.

Wilson, M. (1989). Igneous Petrogenesis. Londres: Harper Collins Academy.

Winter, J. D. (2010). Principles of igneous and metamorphic petrology. $2^{\mathrm{a}}$ ed. Nova York: Prentice Hall. 